أثر استخدام الدعم الإكتروني في بيئة التعلم المدمج القائمة على الفصل المعكوس على التحصيل المعرفي ويقاء أثر التعلم لدى طلاب لهي تكنولوجيا التعليم بجامعة جنوب الوادى لئي

د / أحمد حمي محمد أبوالمجد'

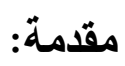

دمج المستحدثات التكنولوجية في العملية التعليمية اصبح ضرورة ملحة في عصر التكنولوجيا الرقمية الذي اصبحت فيها هذه المستحدثات جزء لا يتجزآ من حياه المتعلمين، بما يسهم في حل كثير من المشكلات التي تواجه المؤسسة التعليمية من انفجار معرفي ومواجهه زيادة الاعداد الكبيرة وتغيير خصائص المتعلمين التي لم تعد النظم التقليدية باساليبها التقليدية قادره على تلبية حاجاتهم

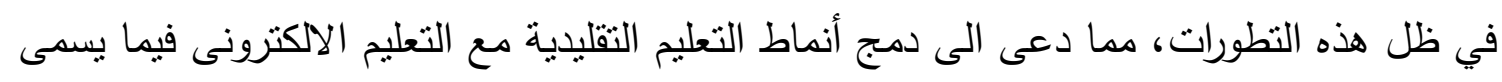
بالتعليم المدمج. واستخدام الدعامات يلعب دور فعال داخل البيئات التعليمية بشكل عام والبيئات الالكترونية بشكل خاص وهى قائمة على النظرية البنائية والتي تعتمد في المقام الأول على الاكتساب الذاتي

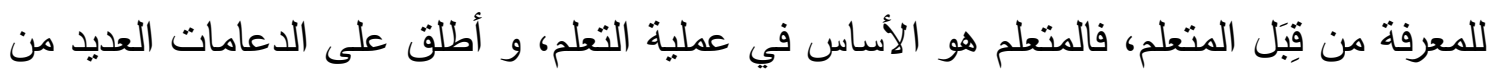
المسميات منها "سقالات التعلم" إعتمادًا على أنها تدعم المتعلم أثناء بنائه لمعارفه ومهاراته مثلها منل السقالات التي تستخدم في أعمال البناء والتشييد، كما أطلق عليها "سنادات التعلم" لتشابهها الوظيفي بينها وبين السنادات المساعدة في عمليات التشييد يستند عليها المتعلم ليرتقي بمستواه المعرفي والمهاري لمستوى أعلى. واطلق أيضًا عليها "مساعدات التعلم "عند قيامها بمساعدت المتعلم في أنجاز مهامه، وقد تطور مفهوم دعامات التعلم البنائية ليصف آليات دعم المتعلم سواء

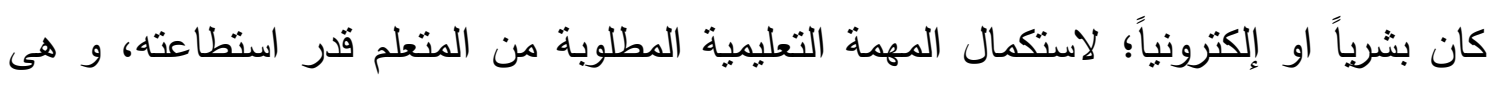
تستخدم في بناء وتدعيم ما يعرفه المتعلم بالفعل للتوصل إلى ما لا يعرفه، من خلال عرض وتقديم العناصر التي يحتاجها وتساعده على التعليم والتعلم (Shapiro, A. M., 2008, p. 30) (حسن

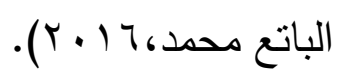




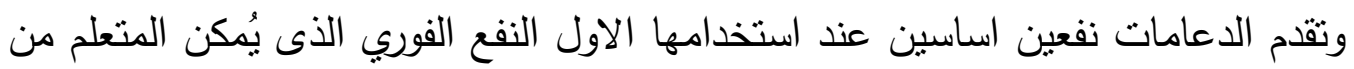

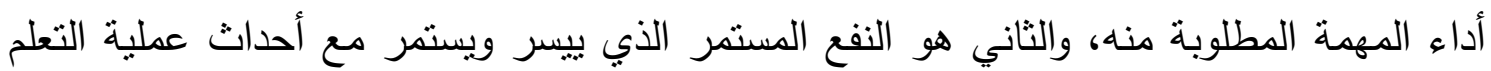

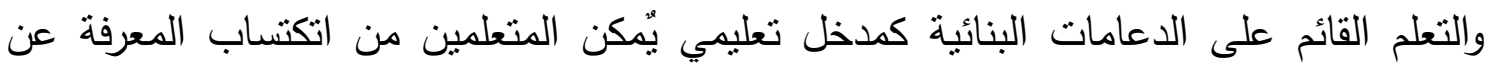

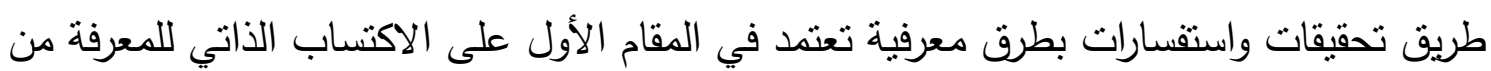

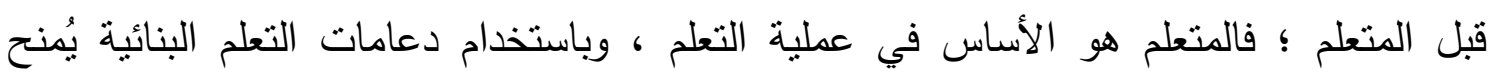

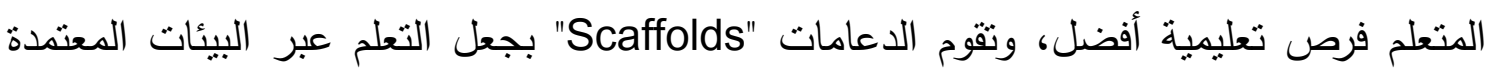
على التكنولوجيا أكثر فاعلية واستمرارية، حيث تتيح له مستوى الدعم الكافي عند الاحتياج اليه لمساعدنه على فهم المحتوى المقدم والوصول بقدراتهم إلى أقصى درجة مدكنةمن التعلم والتفاعل

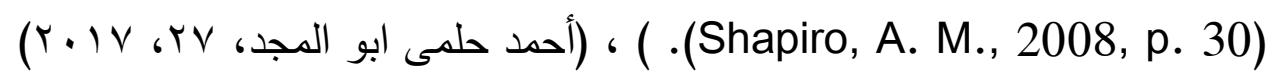

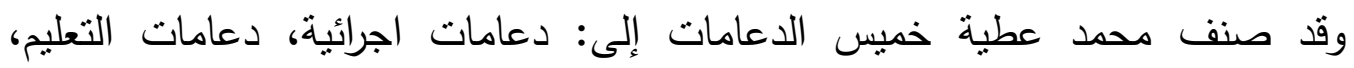

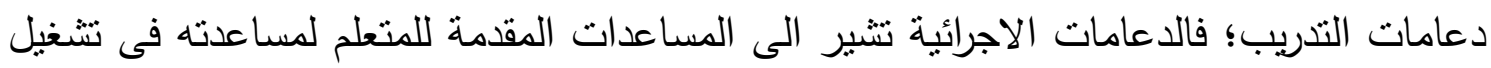

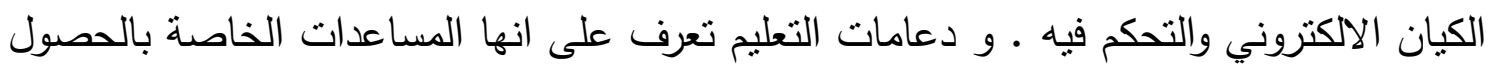

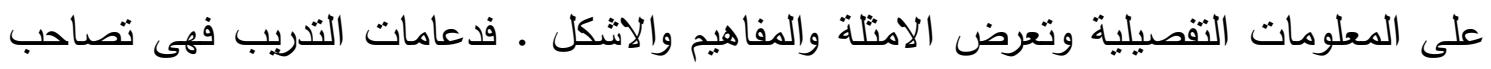

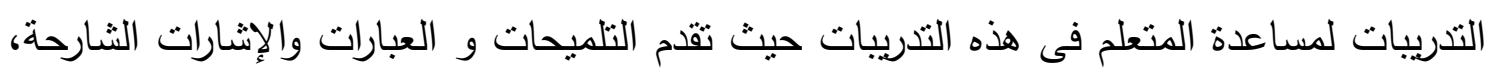
وتساعد الدعامات على جعل التعلم عبر البيئات المعتمدة على التكنولوجيا أكثر دينامية واستمرارية للمتعلمين حيث تقدم لهم أنماط ومستويات الدعم الكافى لمساعدتهم على فهم المحتوى المقدم

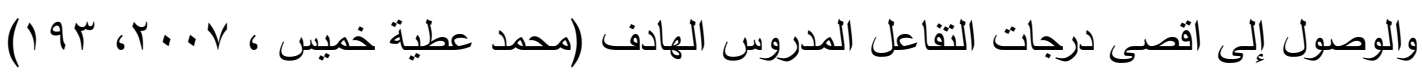

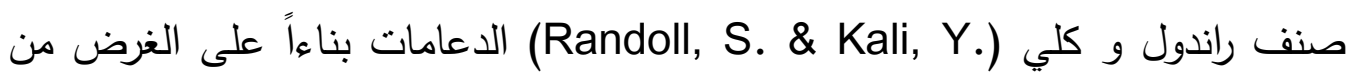
تقديمها، فهناك دعامات المعالجة "Process Scaffolds" التى توجهه المتعلم لمعرفة الطريق والمسارات والتتابعات التي ينبغي أن يسلكها، و سبل التحكم في البرنامج سواء كانت إجبارية أو تواتو

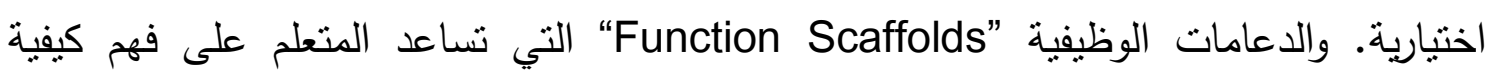
استخدام البرامج والأوامر من خلاد الأمتلة الثارحة. وأيضاً دعامات المحتوى Content"

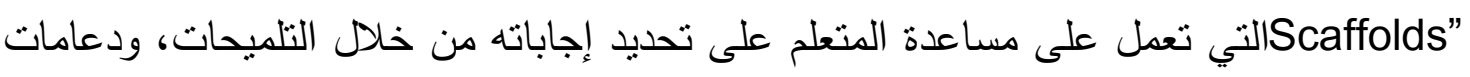

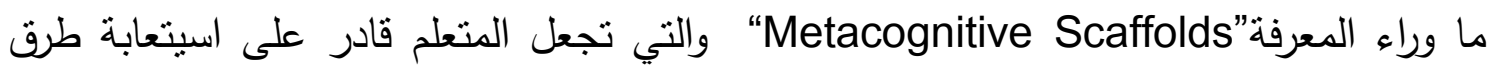
(Randoll, S. \& Kali, Y., إدارة عملية التعلم وبرامجها وتقييم فهمه وعي بانماط تعلمهل 
أثنار كلا من " بارك و كيم (Park \& Kim) الى فوائد استخدام دعامات التعلم البنائية يمكن تحديد أهمها فى؛ معرفة موهبة المتعلم فى وقت مبكر، تقدم دعامات التعلم البنائية بوسائل

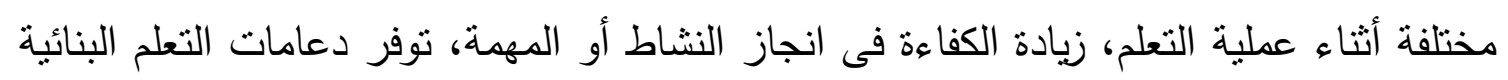

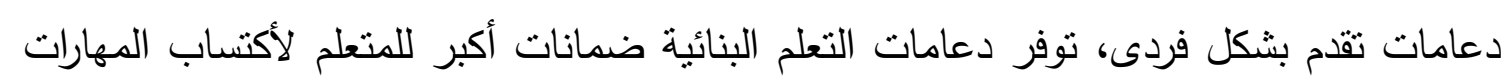

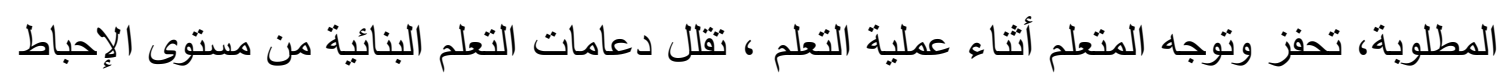

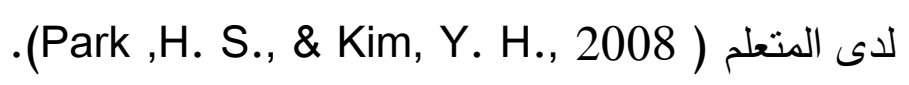
كما أوصى كلا من " براك ، ديفولدر" بالاهتمام بتصميمات متتوعة للدعم في تصميم

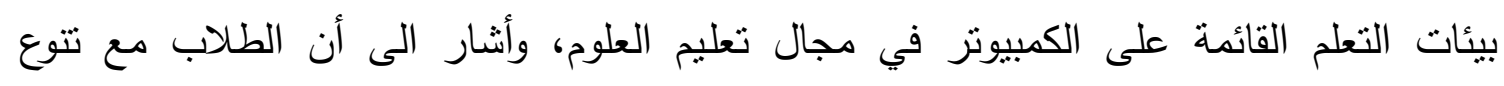
خصائصهم أو خصائص العمل المختلفة تحتاجون إلى مساعدة الدعمات في بيئات التعلم القائم

على الكمبيوتر (A.Devolder, J.vanBraak \& J.Tondeur 2012)

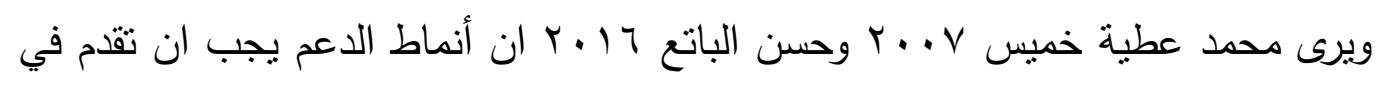

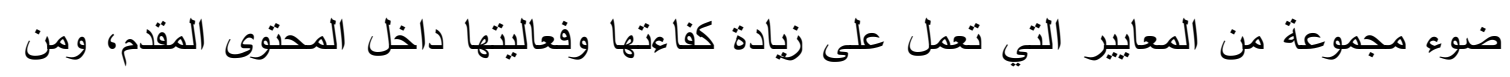

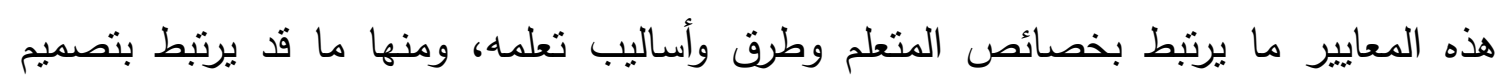

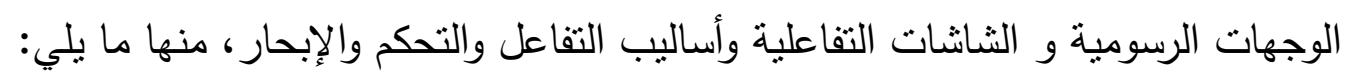

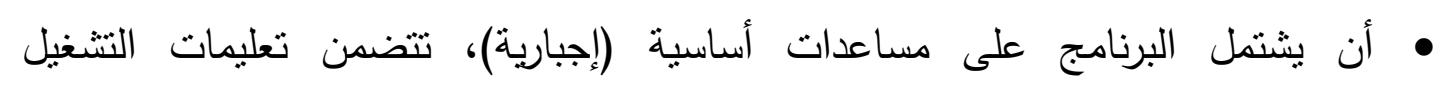

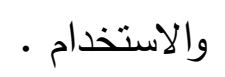

أن يشتمل البرنامج على مساعدات تلقائية تتضمن جملًا إرشادية وعبارات تذكرية، نظهر

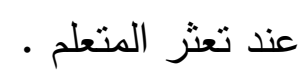

أن يشتمل البرنامج على مساعدات اختيارية (تحت الطلب) نقدم للمتعلم عندما يطلبها .

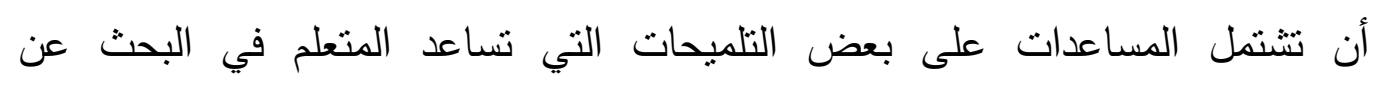

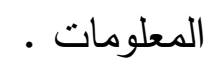

أن نتنمل على بعض الصور والرسوم الخطية البسيطة .

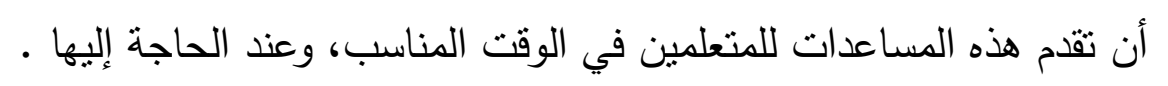
أن تقدم المساعدة دون إيجاز مخل أو تطويل ممل . 
أن توضع في مكان ثابت وموحد في كل الثانشات والصفحات. محمد عطية خميس

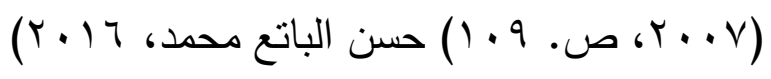

و دعامات التعلم تعد من أهم العناصر الواجب نوافع دافرها في أب بنية أو نظام تعليمي تقليدي

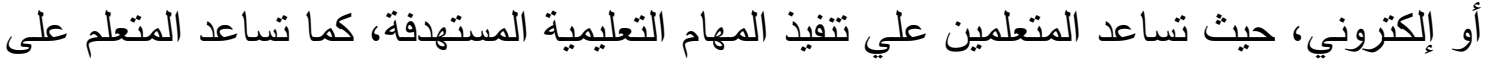
الانتقال من الأسلوب التقليدي الذي ينتقل فيه المتعلم من درس إلي الآخر بطريقة الآلية إلي موقف تعليمي متكامل يقوم فيه المتعلم بمهام عملية وعلمية للوصول إلي التعلم الصحيح المفيد، حيث تساعد الدعامات البنائية علي بناء معرفته والوصول إلي مستوي الإتقان في التعلم، كما تعمل على التى لئه تقليل الفجوة بين ما يعرفه(معرفته السابقة) وما يجب أن يعرفه وينجزه من مهام، وهذا ما يحدث

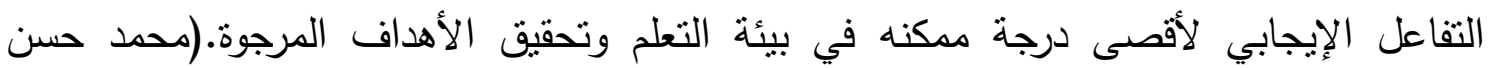

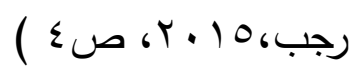

والفصل المعكوس (Flipped classroom) شكل من اشكال التعليم الدمدج توظف فيه التقنيات والمستحدثات التكنووجيا الحديثة لتقديم تعلم يتتاسب مع حاجات المتعلمين ومتطلباتهم المعرفية ، وتعتبر الفصول المعكوسة من الممارسات التي تسعي لنطويع التكنولوجيا الحديثة لتطوير السياق التقليدي حيث يقوم المعلم بإعداد المحتوي التعليمي باستخدام التكنولوجيا السمعية والبصرية وبرامج المحاكاة والتقييم التفاعلي لتكون في متناول المتعلمين قبل الدرس، ومتاحه لهم علي مدار الوقت، وبهذا يتمكن المتعلمون من الاطلاع علي المحتويات سابقة التجهيز حسب احتياجتهم وفى ضوء المنطلبات التعليمية لهم ، حيث يقوم طلاب الفصل بمشاهدة محاضرات

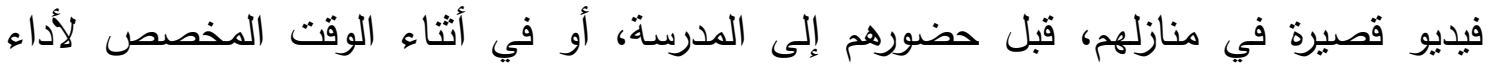

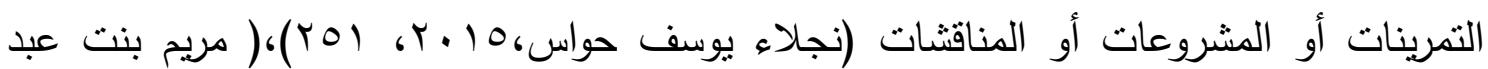

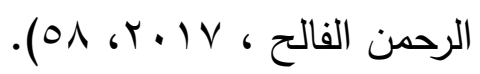

وأنثارت العديد من الدراسـات العربية إلي دور واهمية توظيف واستخدام الفصول المعكوسة

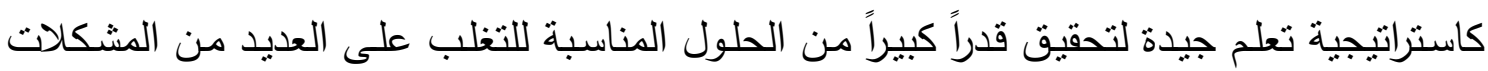

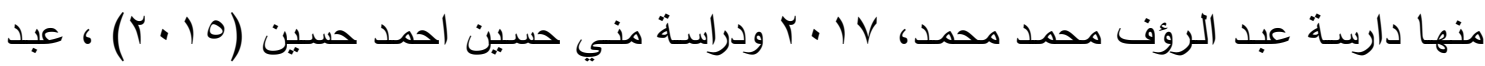

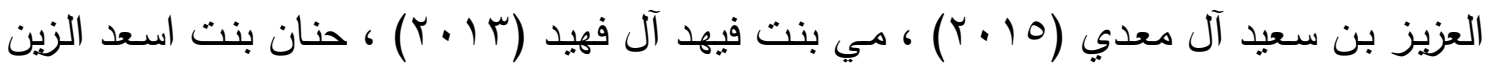

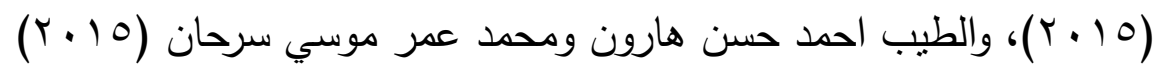


كما أنشارت العديد من الدراسات الاجنبية الى ان فكرة الفصول المعكوسة تعتمد على انعكاس ترتيب تقديم الدروس و التطبيقات والأنشطة لتيكون تقيد الدرس في المنزل والأنشطة داخل الفصل

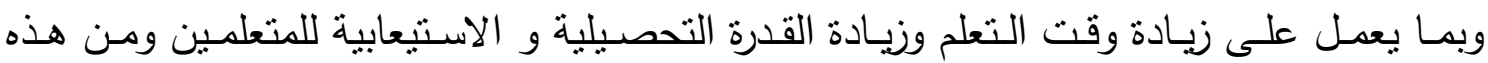
Mary Lane-و ، clyde f.herreid \&Nancy A schiller (2015) الدراسات دراسة yiran Zhao \&Andrew ودراسة Branda Danker (2015) ،Kelso, il Hod,( 2015) Graham Brent Johnsonودراسة، Cara A. Mariowe (2012) ودراسة ho (2014) Michelle ودراسة، Jacob L.Bishop (2013) ، Jeremy F.Stryer (2007)، (2013) . Vaughan (2014) الفصول المعكوسـة كأحد الاستراتيجيات الحديثة التي تعتمد على استخدام المتعلم للتقنيات التعليمية وتوظيفها ، التي تعدل على زيـادة التفاعل بينها وبين المعلم وبين المتعلمين وبعضهم البعض، وتقدم الفصول المعكوسة تمـازج فريد بين نظريتين في التعليم وهما التعلم النشط وتقوم

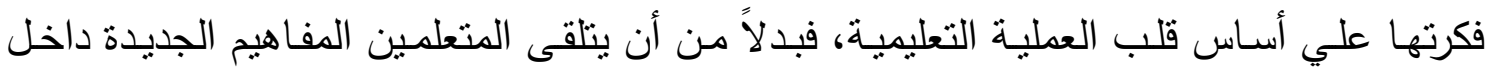
الفصل الدراسي، ثم يعودون إلي المنزل لأداء الواجبات المنزلية في التعليم التقليدي، تقلب العطلية هنا حيث يتلقى الطلاب في التعليم المعكوس المفاهيم الجديدة للدرس في المنزل من خلال إعداد

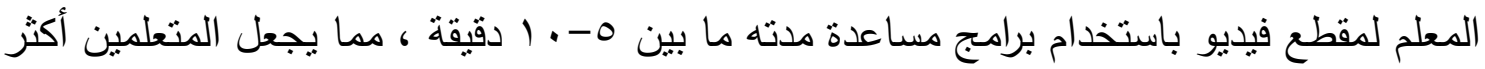

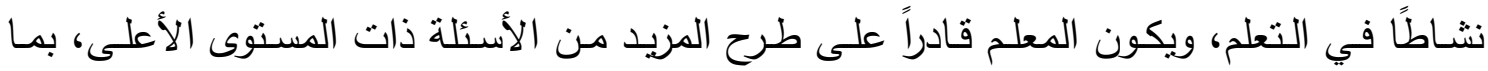
سيعود على عمليات التحصيل بمزيد من من العمق في تغطية المحتوى.(Basel,2015,33)

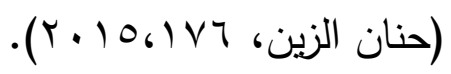

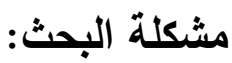

عملية التعلم باستخدام دعامات التعلم "Structure Scaffolds" تتم فى ضوء خطوتين رئيستين الخطوه الأولى؛ تحديد الخطى التعليمية التى تقود المتعلم إلى فهم متعقق لما لا يعرفه من

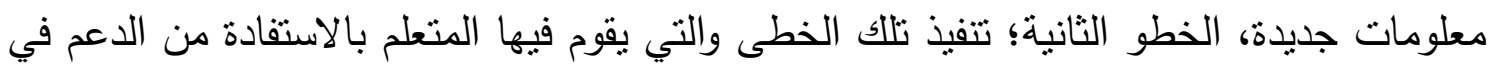
كل خطوة من عملية التعلم(Lange, V. L., 2002)، وان استخدام الدعامات وتوظيفها بكفاءة يمكن أن تكون بمثابة النقطة الأساسية التى تمكنه من التفاعل مع البناء المعرفي واستخدامه بكفاءة فى عمليات التوجيه والإرشاد داخل بيئات التعلم (Liu, Y. H., 2006, p. 43). 
وتتمثل مشكلة البحث الحالي في " الحاجة إلى دراسة نمطى الدعامات البنائية الالكترونية (المسوجزة والتقصيلية ) والتفاعل بينهمـا في بيئة الفصـول المعكوسـة ومدى تأثيرهم على مستوى إلى التحصبل وبقاء اثر التعلم لدى طلاب تكنولوجيـا التعليم" حيث يعد البحث الحسالي أحد بحوث - (Aptitude Treatment-Interaction) التفاعل بين الاستعداد والمعالجة وذلك في محاولة لتوفير معالجة تظهر الاستفادة من الدعامات وتوظيفها بمـا يزيد من فاعلية تاثير الفصول المعكوسة وزيادة كفائتها في العملية التعليمية . أهداف البحث: - (1) يهذف البحث الحالي إلى : مانى

بناء نموذج التصميم التعليمي المقترح يعتمد على نمطى الدعامات الالكترونية (الموجزة /

\section{التفصيلية )}

التعرف على أثر بيئة الفصل المعكوس القائمة على الدعامات الموجزة على تحصيل الجانب المعرفي وبقاء اثر التعلم لطلاب تكنولوجيا التعليم. التعرف على أثز بيئة الفصل المعكوس القائمة على الدعامات التقصيلية على تحصيل الجانب المعرفي وبقاء اثر التعلم لطلاب تكنولوجيا التعليم.

\section{أهمية البحث:}

تتمثن أهمية البحث فيما يلى :

• استجابة للتوجهات الحديثة في مجال توظيف تكنولوجيا التعليم و المعلومات

$$
\text { والاتصالات وتطبيقاتها في الميدان التعليمى. }
$$

•الحاجة الماسة لدراسة أثر الدمج بين التعليم التقليدي والتعليم الاكتروني لتحقيق الأهداف التعليمية المنشودة بمايضمن وجود المعلم والتقاعل معه وجها لوجه واستخدام التقنيات التكنولوجية الحديثة في التعليم.

قد تسهم نتائج البحث في تعزيز الإفادة من إمكانيات الفصول المعكوسة في تذليل الصعوبات التي تواجه الطلاب عند دراسة بعض المقررات الدراسية. قد تقيد نتائج البحث الباحثين في مجال تكنولوجيا التعليم بالقيام بإجراء أبحاث أخرى تتتاول جوانب أخرى في هذا الموضوع. 
يمكن النظر إلى نتائج هذا البحث وتفسيرها في ضوء الحدود التالية:

ا ـ استخدام نمطي الدعامات البنائية الالكتروينة الموجزة والتقصيلية

r. بيئة التعلم الكترونية قائمة على الفصول المعكوسة.

r. مهارات إنتاج برامج الفيديو والتليفزيون (استخدام كاميرا الفيديو والتليفزيون

$$
\text { - تهيئيها للاستخدام ). }
$$

ع. عينة دن طلاب الفرقة الرابعة تكنولوجيا التعليم بكلية التربية النوعية

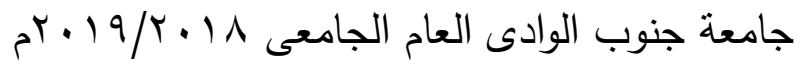$$
\text { أدوات البحث: }
$$

ا ـ بيئة الفصول المعكوسة التي تعتمد على نمط الدعامات الموجزة.

r. بيئة الفصول المعكوسة التي تعتمد على نمط الدعامات التفصيلية.

r. اختبار تحصيلي لقياس الجانب المعرفي (من إعداد الباحث).

$$
\text { ع. اختبار ادائى لقياس الجانب المهارى (من إعداد الباحث). }
$$

\section{منهج البحث:}

في ضوء طبيعة البحث نم استخدم المنهج الوصفي والمنهج التجريبى لاتمام اجراءات

البحث والحصول على النتائج ، حيث تم استخدام المنهج الوصفى فى دراسة و تحليل الادبيات و

البحوث والدراسات السابقة، والمنهج التجريبي فى بناء واستخدام المعالجة التجربيية للبحث.

\begin{tabular}{|c|c|c|c|c|}
\hline القياس البعدى & المتغير التابع & المتغير المستقل / المعالجة التجريبية & القياس القبلي & المجموعات \\
\hline * & التحصيل & بيئة الفصل المعكوس المدعومة & * & المجموعة التجريبية \\
\hline * & كفاءة التعلم & بيئة الفصل المعكوس المدعومة & * & المجموعة التجريبية \\
\hline
\end{tabular}

ثالثاً: التصميم التجريبي:

يوضح جدول (1) التصميم التجريبي للبحث: مخطط التصميم التجريبي ذا المجموعتين التجربيية 
تم بناء التصميم التجريبيى للبحث كما يلى: - المجموعة التجريبية الاولى يتم التعلم من خلال بيئة الفصل المعكوس المدعومة بالدعامات

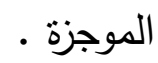

- المجموعة التجريبية الثانية ويتم التعلم من خلال بيئة الفصل المعكوس المدعومة بالدعامات

$$
\text { متغيرات البحث: }
$$

- بيئة الفصل المعكوس المدعومة بالدعامات الموجزة.

- مبيئة الفصل المعكوس المدعومة بالدعامات التفصيلية.

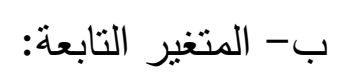

- - التحصيل المعرفى لدى طلاب تكنولوجيا التعليم كلية التربية النوعية جامعة

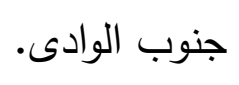

- كفاءة التعلم لطلاب تكنولوجيا التعليم كلية التربية النوعية جامعة جنوب الوادى.

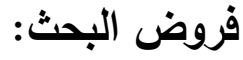

بسعي البحث إلى اختبار الفروض التالية:

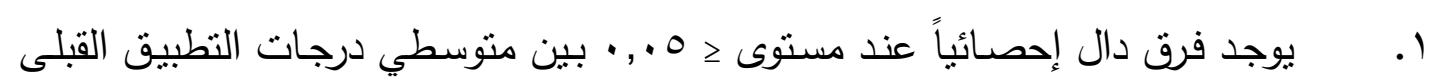

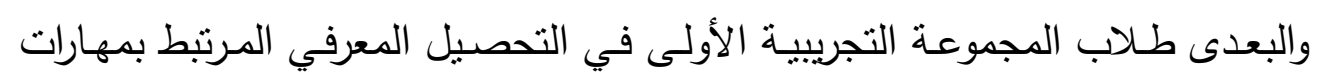

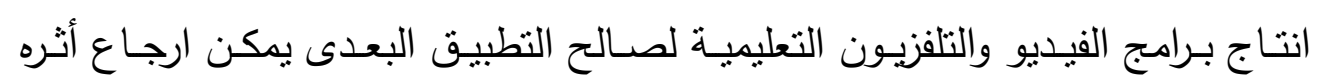

لاستخدام الفصول المعكوسة القائمة على الدعامات.

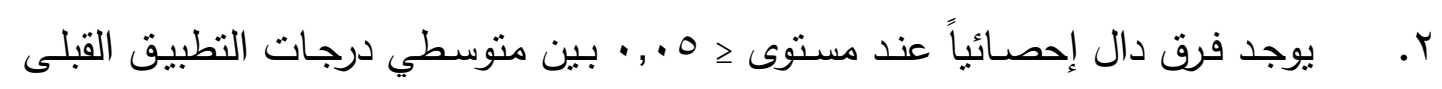

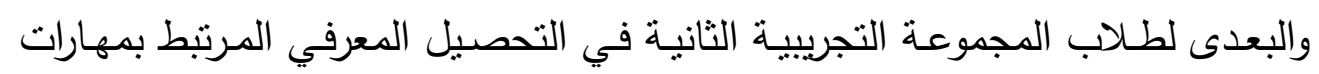

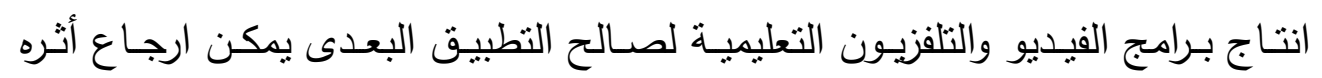

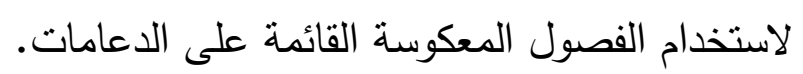

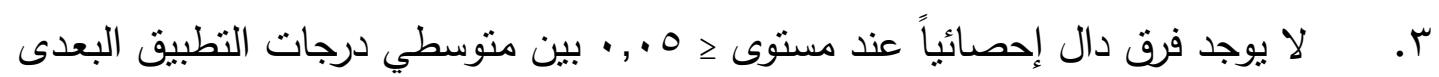

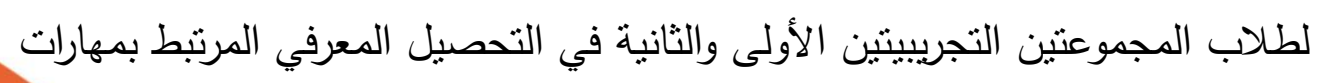


انتاج برامج الفيديو والتلفزيون التعليمية عند استخدام الفصول المعكوسة يمكن ارجاع الإع التهاع الأثر الأساسي لها لنمط الدعامات.

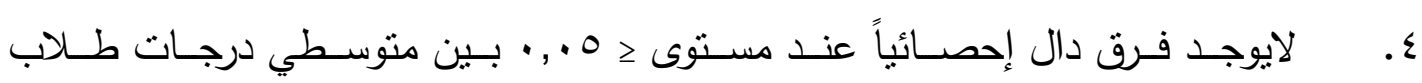

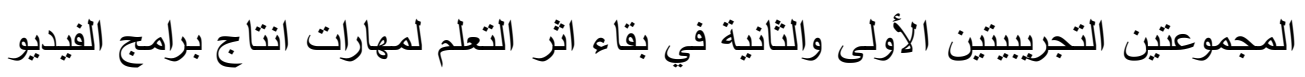

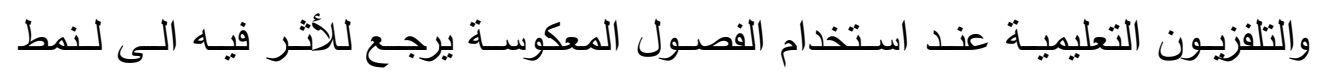

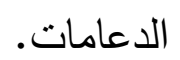

الأساليب الإحصائية: - n

"Statistical Packages for تم استخدام برنامج الحزم الإحصائية للعلوم الإجتماعنة Social Sciences SPSS 26". لمعالجة بيانات التجربة وقد تم تفسير النتائج في ضوء الإعة اهداف

$$
\text { وفروض البحث. }
$$

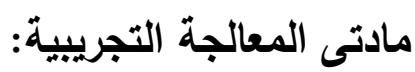

تكونت مادتى المعالجة التجريبية ( بيئى الفصل المعكوس) متمنلنين من حيث الأهداف

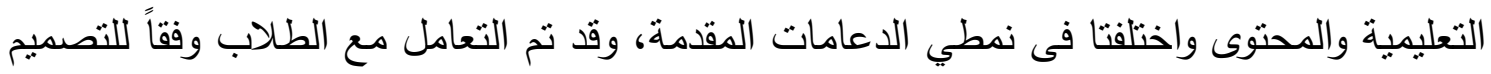

$$
\text { مصطلحات البحث: التصنيفى للبحث }
$$

الفصل المعكوس Flipped-Classroom Style:

يعرف الفصل المعكوس بانه " أحد اثكال التعليم المدمج الذب يقوم فيه الطلاب من

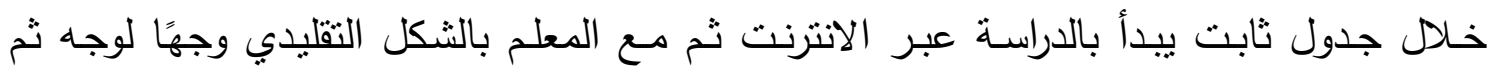

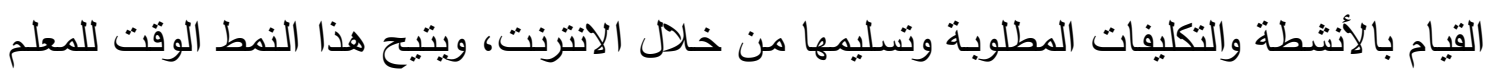
لتوجيه المتعلمين وتقديم النصائح للمتعلمين حول تعلمهم" (horn,2012,78) .

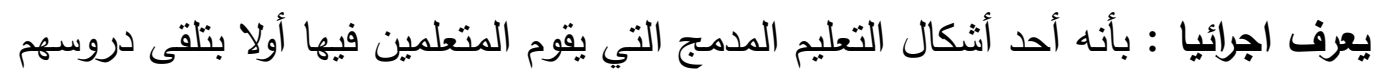

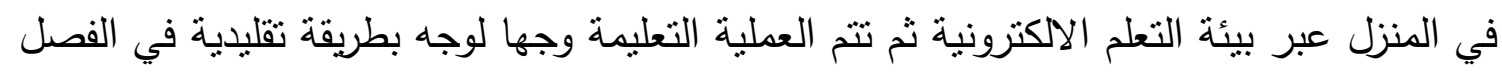

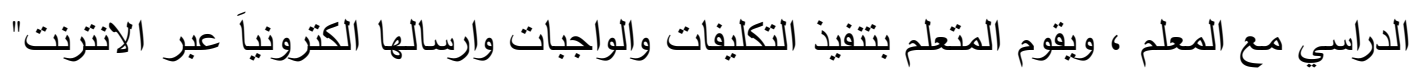
نمط الفصل المعكوس المدعوم بالدعامات الموجزة : يعرف الفصل المعكوس اجرائيا في البحث الحسالي بانهـ : نمط يتواصل فئل فيه الطـلاب مـع 


\section{د/ أحمد حلي محمد أبوالمجد}

محتوي مقرر انتاج برامج الفيديو والتليفزيون ، ثم اتاحة الفرصة للطلاب باختيار الانشطة والادوات

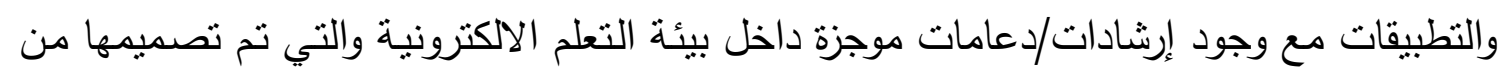
اجل تحقيق اهداف تعليمية محددة .

\section{نمط الفصل المعكوس المدعوم بالدعامات التفصيلية :}

يعرف الفصل المعكوس اجرائيا في البحث الحسالي بانـه : نمط يتواصل فيـه الطـلاب مـع محتوي مقرر انتاج برامج الفيديو والتليفزيون ، ثم اتاحة الفرصة للطلاب باختيار الانشطة والادوات والتطبيقات مـ وجود إرشادات/دعامات تفصيلية داخل بيئة التعلم الالكترونية والتي تم تصميمها من اجل تحقيق اهداف تعليمية محددة . الاعامات البنائية Structure Scaffolds وعرفها "فينكى " بأنها:" منظومة من الأدوات والاستراتيجيات والعمليات والطرق التى يتم تخطيطها وتصميمها بشكل محكم، بحيث يتم تقديمها أثناء عمليات التعلم عندما بكون المتعلم فى بـ Verenikina, ) "حاجة لها ولن تسنطيع التقدم بدونها، ويتم سحبها بمجرد تحقيق الهدف منها" .$(2004$

ويعرفها "هيزر" بانها اسلوب تعليمي يرتبط بمنطقة التتمية القريبة للمتعلم، والذي يحرص المعلم على معرفتها جيدا، ودعمها بشكل فردى لكل متعلم عن طريق تحسين قدرته تدريجياً على بناء المعرفة السابقة، ويمكن استخدام الدعامات في مجموعات منتوعة من المحتوى بما يتتاسب مع

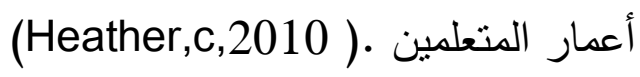
وتعرف اجرائيا في نطاق البحث الحالي بانها " جسور الإمدادات النشطة التى تدعم الطالب وتساعده عملية التعلم وإنجاز المهام والأهداف المرجوة من الانشطة و استخدام التطبيقات والانتقال من مستوى إلى الذى يليه فى سياق يكون فيه الطالب نشطًا ومتفاعلاً، بحيث تذعم البناء المعرفى والمهارى لديه " المانيه الإطار النظري

أولا: الفصول المعكوبة:

الفصول المعكوسـة احد الحلول التكنولوجية الحديثة التي تدعم مبادئ النظريـة البنائية التى تقود إلى معتقدات جديدة حول التميز والابداع في التعليم والتعلم، والتجديد في أدوار المعلمين 


\section{د/ أحمد حلمي محمد أبوالمجد}

والطلبة في عملية التعليم والتعلم لعلاج ضعف التعلم التقليدي وتتمية مستوي مهارات التفكير حيث يقوم الطلاب بمشـاهدة عروض فيديو قصير للمحاضرات في المنزل ويقى وقت الفصل لمناقتـة المحتوي مع المعلم ، مما يعطى فرصة للمعلم للتفاعل ومناقتة الطلاب في الفصل التقليدى والعمل كميسر أو مساند للتعلم بدلاً من ناقل للمعرفة ، في ضوء التأكيد على ان الطالب هو المسؤول عن التعلم الخاص به (Brame , Cynthia J,2013) وتقوم الفصول المعكوسة على ان التعلم هو عملية بنائية نشطة تعتمد على استخدام الفيديو التعليمي بشكل يساعد الطالب على تعديل ابنيته المعرفية وإعادة تشكيل الهيكل المعرفية للافكار والمعارف والمفاهيم، مما يسـاعد على ترسيخ المعرفة أو الفهم، ويمكن للمتعلمين استخدام وقت الحصة لتفسير تلك التجربة الجديدة بناء على ما هو معروف بالفعل Ray \& Powell,2014)

فالفصـول المعكوسـة تتوافق مـع النظريـة البنائيـة و مـاتراه حـول التميز والابـداع في التعليم والتعلم، والتجديد في أدوار المعلمين والطلبة في عملية التعليم والتعلم التي تجعل الطالب هو محور العملية التعليمية ويتغير دور المعلم فيها من ملقن للمعلومات إلي موجه وميسر، في بيئة تعلم مرنه تهتم بالتعلم ذي المعني الذي يحدث من خلا الأنشطة الحقيقية التي تساعد المتعلم في بناء الفهم وتتمية المهارات المناسبة لحل المشكلات حيث يقوم التلاميذ باستخدام التقنية بالبحث عن المعلومة وبناء معارفه ومعلوماته بنفسه فهو باحث ومثـارك في بناء معلوماته ومعارفه، والفصل المعكوس ومقاطع الفيديو عبر الإنترنت يدعم مبادئ البنائية عن طريق تحرير وقت الفصل الدراسـي إلى

\section{الاستقصاء (Gerald Robert Overmyer,2014,9).}

\section{أسس وخصائص الفصل المعكوس أرس}

الفصل المعكوس بيئة نتتوع وتتعدد فيها أثكال التفاعل والمشاركة النشطة و يتفاعل الطلاب مع المعلم من خلال التدريبات ومع بعضهم البعض من خلال المشاركة في الأنشطة بشكل فردي اومن خلال مجموعات صغيره مما يزبد من دافعية الطلاب لتعلم وإنجاز المهارات المطلوبـة ، ومن اهم خصائص الفصل المعكوس التي يمكن ان تستمد من كلمة ( FLIP ) بانه: • بيئة مرنـة F (flexible environment) التعليم المعكوس يسمح بأنماط تعليمية

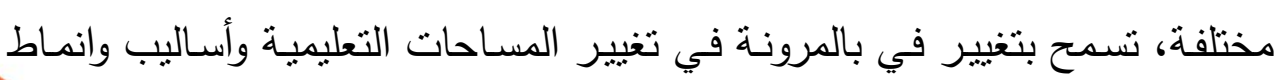


التعلم وتتوع طرق تقييم الطلاب.

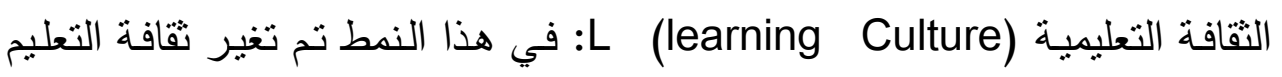

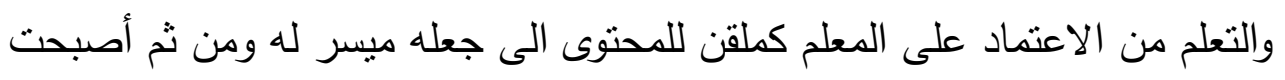
العملية التعليمية ترتكز على الطالب ونشاطه وتفاعله وتجعله ينخرط في عملية البناء

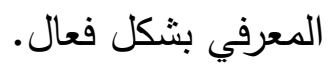
المحتوي المرغوب فيه(intentional content) I : معلمو التعليم المعكوس دائمو

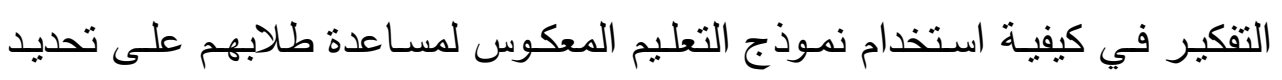

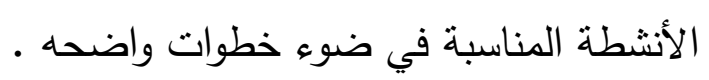

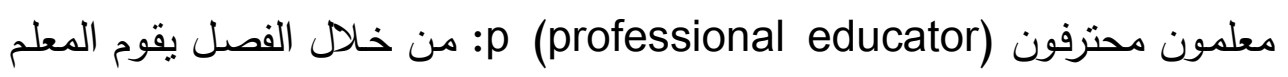
بشكل احترافى و مستمر بملاحظـة طلابـه ويقوم بتقديم تغذيـة راجعـة لهم وتقيبم ومراجعة اعمالهم. (Zappe Leicht, \&)(flipped learning network 2014)

Messner.I \& Lee , 2009) و تعتمد الفصول المعكوسة على أسس أهمها:

نقل المحاضرة خارج الفصل الدراسي عن طريق التكنولئ النوبيا

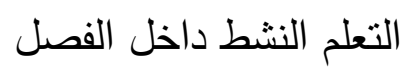
تعلم ذاتي خارج الفصل • تعلم مفرد وتعاوني مشترك داخل الفصل

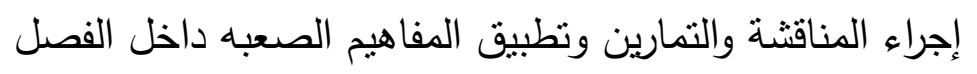

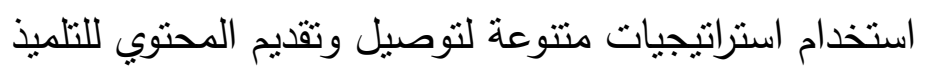
التركيز علي الطالب والتعلم(Bergmann, sams,2014)

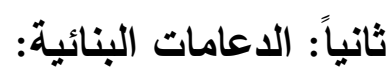

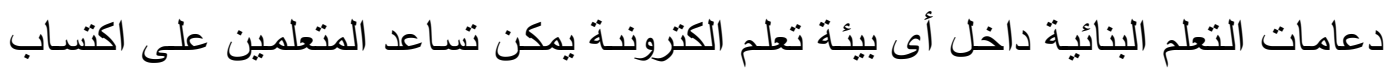

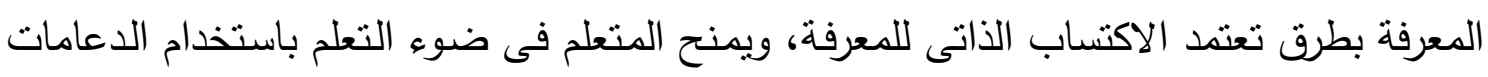

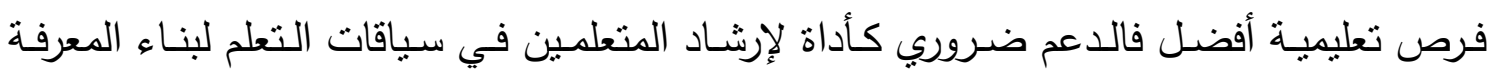

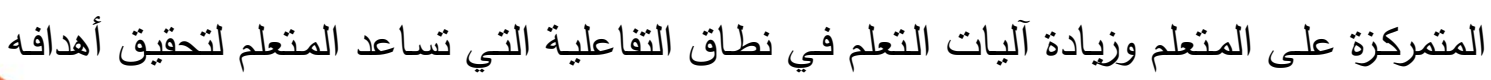


.(Stewart, T. M., et al, 2007, pp. 77-78)

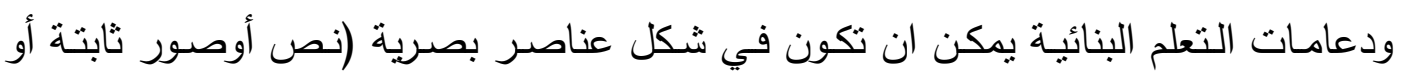

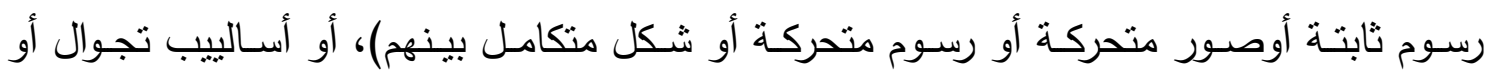

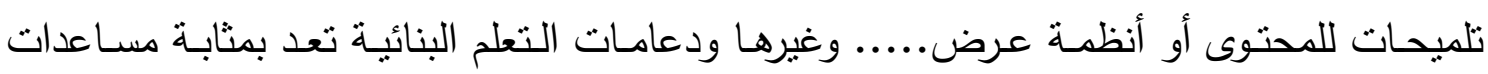

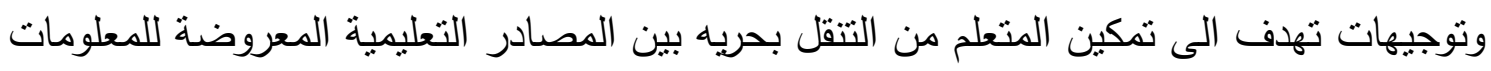

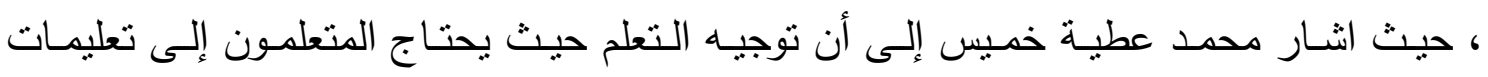

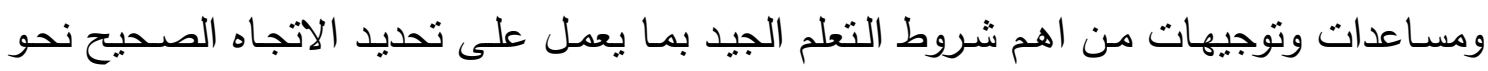

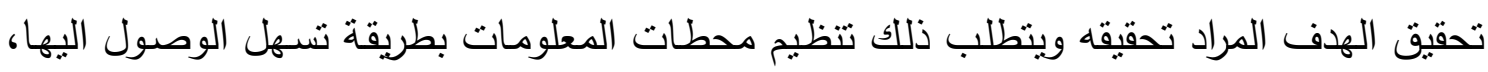
خاصة المحطات التى تربطها علاقة بحيث توضح اتجاه السير من محطة الى أخرى، وامكانية

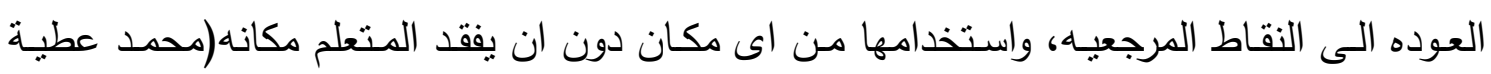

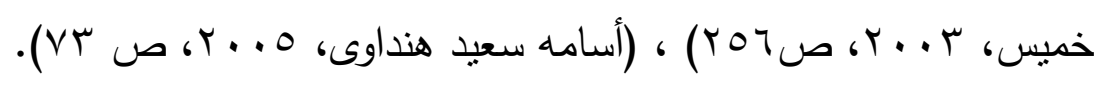

وهناك عديد من الدراسات والبحوث التى تتاولت دعامات التعلم البنائية وفعاليتها فى تقديم

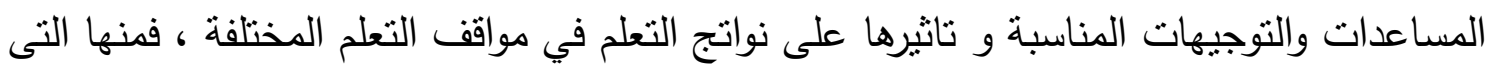

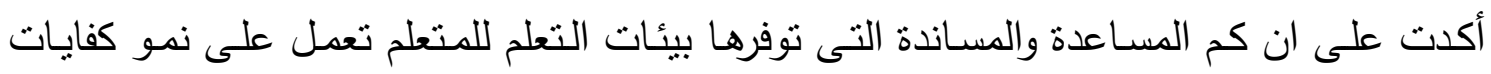
المتعلم وتوفر له قدر من الثقة تتيح له ان يستدعى ويستخدم معرفته السابقة لإنجاز مهمه التعلم أو ربطها بالمعرفة الجديدة (2001 (McLoughlin, C. \& Hollingworth, R.

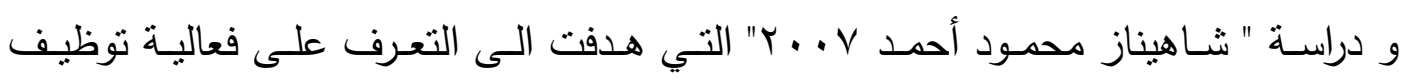

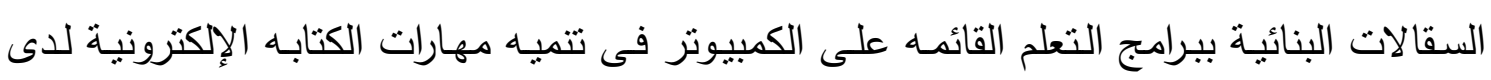
الطالبات معلمات اللغة الإنجليزية (ثاهيناز محمود، V. . ب).

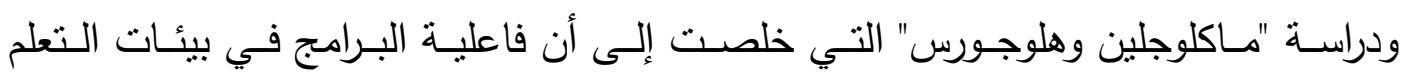

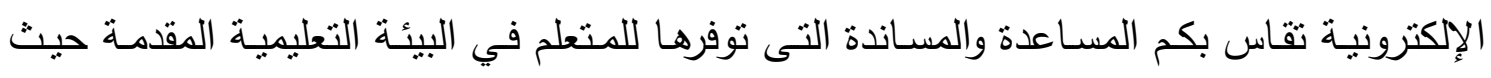

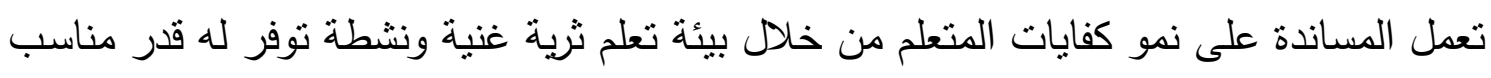

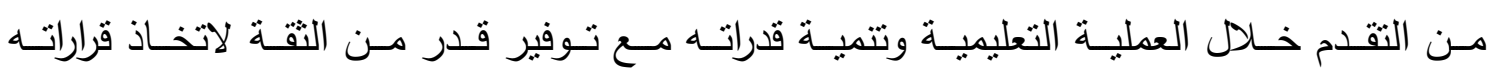

.(McLoughlin, C. \& Hollingworth, R. 2001) ودراسة "ريتل جونسون وكودينجر " التي اثارت الى تأثثر الدعامات المصممة للمساعدة في 
اكتساب المفاهيم الرياضية وحل المسائل، والتي أوضحت التأثثر الايجابى لهذه الدعامات كأداة

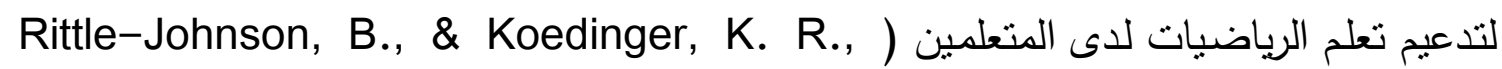
. 2005 ودراسة "دباغ وكينسانتا " لتأثير استخدام أدوات التواصل التعليمية كدعامات تعلم على المواقع

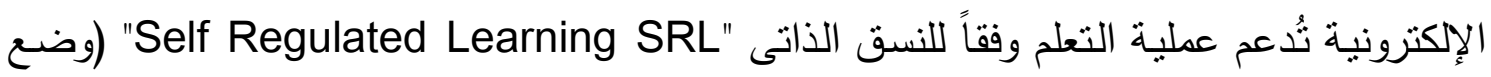

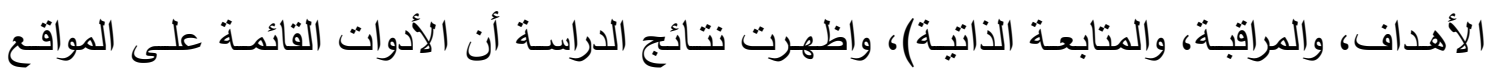

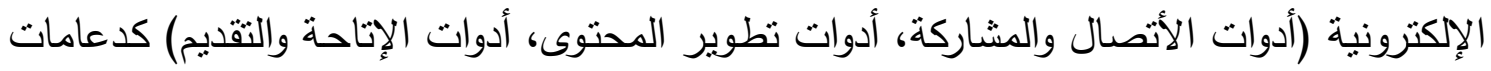

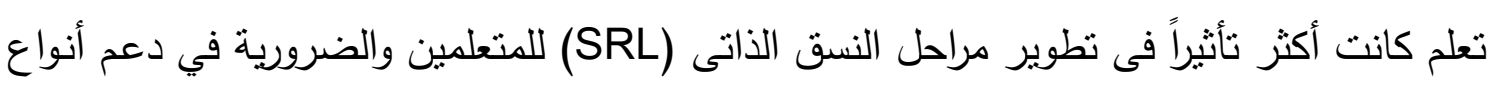

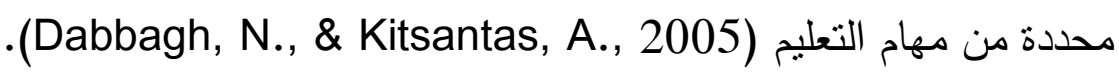
كما اوضحت دراسة "ماكنيل وآخرون .McNeill et al" تأثنير التقديم أو الحذف التدريجي للاعامات "Fading Scaffolds" في مسـاعدة الطلاب لتفسير وبناء الحقائق العلميـة، وأثبتت الدراسة وجود مخرجات تعلم هامة بالنسبة للمتعلمين فى جميع مكونات التفسير العلمي نتيجة تقديم

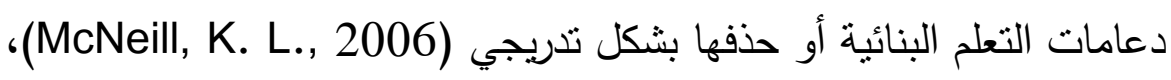

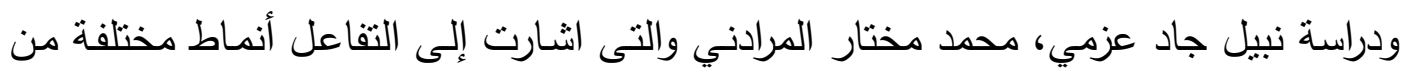

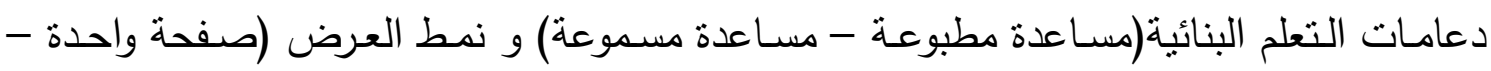

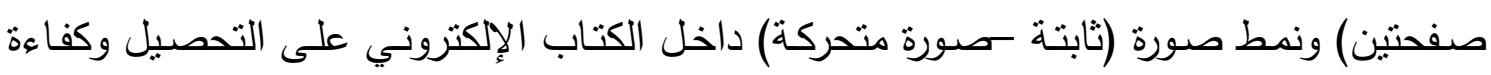

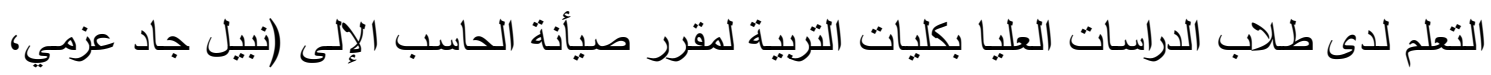

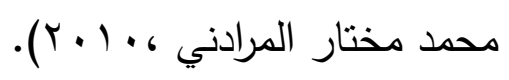

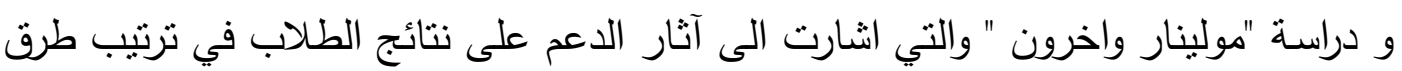

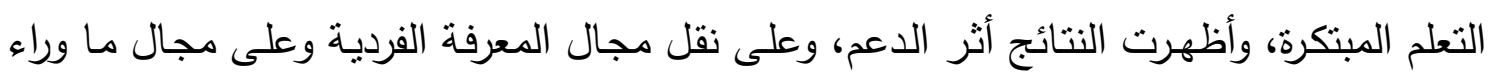
المعرفة الفردية المكتسبة، (Molenaar,l; et al,2011) ودراسة وليد يوسف محمد التى هدفت الى تحديد نوع دعامات التعلم الأنسب (العامة، مقابل

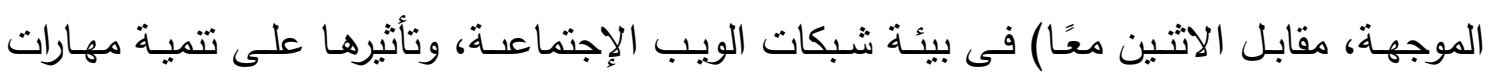

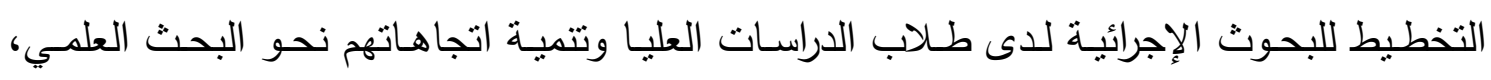

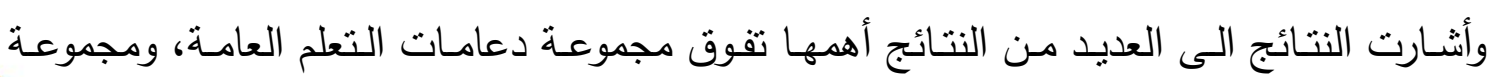




\section{د/ أحمد حلمي محمد أبوالمجد}

دعامـات التعلم العامـة والموجهة معًا مقابـل مجموعـة دعامـات التعلم الموجهـة فقط في مهارات التخطيط للبحوث الإجرائية لدى طلاب الدراسات العليا(وليد يوسف محمد، ـ ( ب ). دراسـة محمد عيد فارس(1 ( • ب) والتي اشـارت الى الدعامات التعليمية وتاثيرها وان تقديمها اثتاء القيام بالانشطة والمهام التعليمية ساعد على التركيز ورفع قدرة التلاميذ ، وعمل على الارتقاء بالمستوى المهارى من خلال الربط بين المعلومات الجديدة والمعارف السابقة لديهم من خلال تقديم المسـاندة والتى تمثلت فى الدعامات التى قدمت اليهم مـن خـلال البرنـامج (محمد عيد فـارس،

$(r \cdot) \Lambda$

\section{معايير بناعالاعامات في بيئات الفصول المعكوسة :}

تمتلك الدعامات العديد من الفوائد التربويـة المميزة التي يمكن ان تقدمها للمتعلم في البيئة التعليمية الإلكترونية، و قد أوصىى "دفولدر وبراك " باقتراح تصميمات متتوعة للدعامات التعليمية

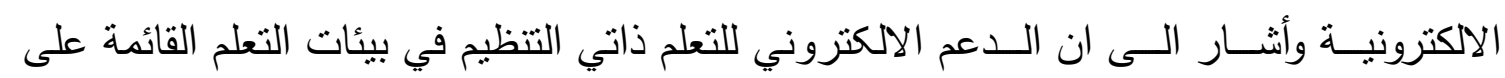
الكمبيوتز في مجال تعليم العلوم ذو فاعلية اذا ما احسن اختيار الأمثل منها وما يناسب خصاص

المتعلمين ( Devolder J, Braak, J (2012) وان التدعيم والدعامات البنائية في بيئات التعلم الإكترونية أفردت العديد من مؤسسات التعليم الإلكتروني مجموعة من المعايير تحدد الملامح والحدود المطلوب توفرها في الدعم ببيئات التعلم الرقمية بهدف ضمان جودة التعليم المقدم ، وهى في مضمونها تعنى كم المساعدة والتخذيـة الراجعة التى توفرها هذه الدعامات للبيئة القائمـة فيها غير انها تمتلك مجموعة من الخصائص/ المعايير

$$
\text { يمكن تحديدها فيما يلى: }
$$

- معامات التعلم البنائية تقدم إتجاهات واضحة Scaffolding Provides Clear -

يحاول المصمدون التربويون فيـه تُوقع المشـاكل التى يتعرض لها Directions:

المتعلم والقيام بكتابة اتجاهات ارشادية للمتعلم خطوة بخطوة لشرح وتفسير ما يجب

عمله، لمقابلة توقعات المتعلمين وحل مشاكلهم فى عمليات التوجية والارشاد.

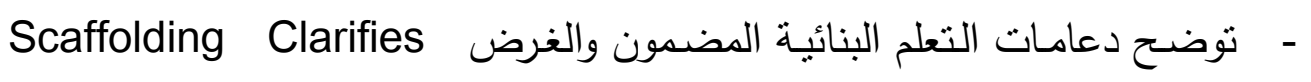

: فالطلاب من خلال استخدام دعامات التعلم البنائية لا ينزلقون نحو : Purpose

تحصيل بسيط، ولا يتم حصارهم فى نشاط غير مخطط له، بل يكون التعلم فاعلا 


\section{/ أحمد حلمي محمد أبوالمبد}

لمرحلة الفكرة واستكثاف المعنى وتطوبر الرؤية والبصيرة .

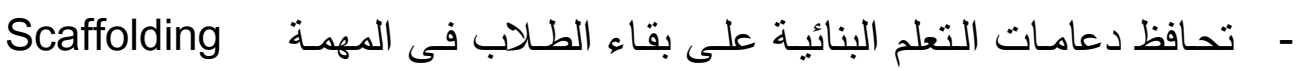
Keeps Students on Task واضحاً للمتعلم فدعامات التعلم البنائية تعد كحائط صد عن الخروج عن الطريق المحدد وتعمل على تحدد الطريق او المسار التعليمى بدون مخاطر الخروج منها ـ Scaffolding تقدم دعامـات التعلم البنائية خاصية التقدير لتوضيح التوقعات Offers Assessment to Clarify Expectations البنائيـة التوقعـات وتقوم بـدمج وإدراج واتحـاد التقدير والتغذيـة الراجعـة ، وتكـون التوقعات واضـحة حيث يتم توضيح الأمنلة النموذجيـة التوضيحية ، العناوين ، المقاييس ومعايير تميز للطلاب منذ بداية النشاط. - توجه دعامـات التعلم البنائية الطلاب نحو المصـادر ذات القيمة Scaffolding Points Students to Worthy Sources بتحديد أفضل مصـادر المعلومات الجيدة بحيث يتسـارع الطـلاب الى تحديد هذه المصـادر بـلا مـن الغرق فى مصـادر معلومـات غير جديرة بالاهتمـام .كما ان دعامات التعلم البنائية تقوم بالخدمة كمقدمة Introduction وليست كسياج حارس بما يساعد على عدم ضياع الوقت وتحديد الأولوية التعليمية.

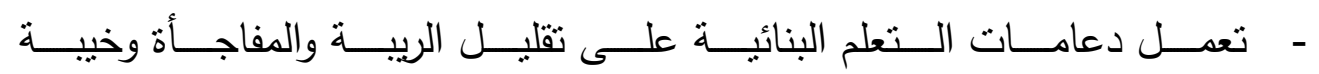
Scaffolding Reduces Uncertainty, Surprise and الأمـل Disappointment البنائية بما يضمن ازالة الاحباطات المشتنة وزيادة الاستفادة من عناصر عملية • التعليم

Scaffolding Delivers تقدم دعامات التعلم البنائية الاتاحة والكفاءة والفاعلية : : : : : :ثث يتم انجاز العمل باستخدام دعامات التعلم البنائية تعمل على توجيـة الطـلاب فى قنوات تقوم بـالتركيز على المهمهة وتوضيحها وتحديد الزمن الخاص بالمهمة مع عدم التعرض لأخطار التجول الالكترونى عبر الإنترنت . 


\section{د/ أحمد حلمي محمد أبوالمجد}

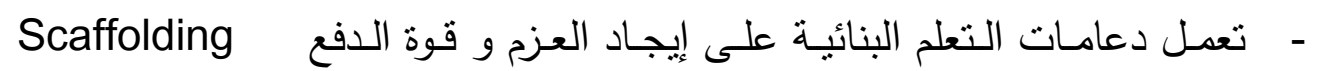

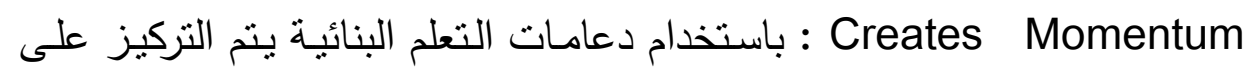
طاقات الطلاب وتوجيهها بطرق تعمل عدم استتفاذ الكثير من الطاقات وتبديدها

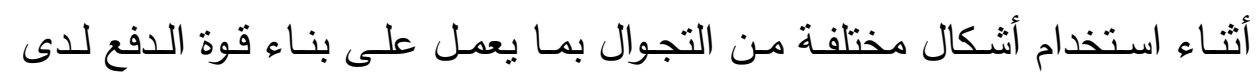
المتعلم.(Vtewart, T. M., 2007)، (Van Der, R.,2002)، استخدام الاعامات فى بيئة الفصل المعكوس ظهر الاهتمـام بالدعم الالكتروني التعليمي المقدم من خـلال البيئـات التعليميـة الالكترونيـة والنظر اليه على أسس علمية وتربوية مستمدة من نظريات التعلم كالاتصالية والبنائية، والتي تشير الي ان دعم المتعلمين يتت من خلال التواصل والتفاعل والتتـارك، بما يتلاءم مع خصائص بيئة Terms of provide التعلم المقدمه بها الدعم، يرى"محمد حسن " أن تقديم دعامات التعلم البنائية Scaffolding مهامه وتمكنة من الترقى الى أعلي مستويات التفكير ، ويمكن تحديد اهم شروط استخدام الدعامات الالكترونية فيما يلى :

ا ـ تصمم العملية التعليمية وفقًا للنظريـة البنائية، وتقدم المواقف والمهام التعليميـة في سياق اجتماعي نشط، بتلقي فيها المتعلم توجيهات ودعامات خارجية. r. تقدم المهام التعليمية والخبرات المستهدفة في سياق حقيقي وجديد علي المتعلم. r. تقدم الدعامات في اللحظة المناسبة لاحتياج المتعلم ولا يستطيع التقدم في المهمة بدونها. ع. تقدم الدعامات لتساعد المتعلم ولا تتصب فقط علي المهمة أو المشكلة ذاتها. 0. تكون دعامـات التعلم المستخدمة جديدة ومؤقتة وليست أداة تستخدم بشـل أساسـي في الموقف المُشكل وبالتالي لا بمكن سحبها منه. 7. تُقوم منظومـة الدعم علي اجراءات محددة تضمن تحقيق الغايـة من الدعم، وتحدد طرق لهات Green field, ) ومعايير تقديمها وأثكالها وأدواتها وأنواعها ومستوياتها وتوقيت سحبهاءهاء

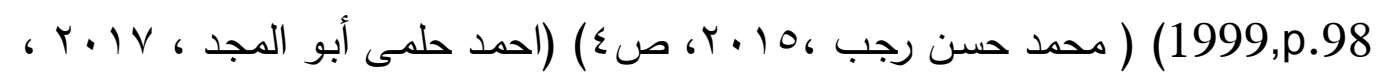
وقد حدد "جرين فيلدر Green field خمس اسباب لاستخدام دعامـات التعلم، يمكن 
تلخيصها فيما بلي:

ا ـ إمداد المتعلمين بالدعم اللازم لمساعدتهم في أنجاز مهامهم التعليمية. r. تنسـيل وتيسر الوصـول إلي مستوي الإتقان في التعلم بنوظيف الأدوات والإسـتراتيجيات

المختلفة.

ب. تعمل علي توسيع مجال التعلم وتحولـه من الصـورة التقليديـة الآلية إلي الصـورة العمليـة البنائية.

ع. تُمكن المتعلمين من أنجاز مهامهج علي أعلي درجة من الجودة.

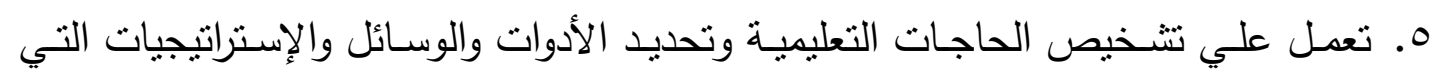
يمكن أن تساعد في تحقيق الإشباع.

أنواع الاعامات البنائية Types of scoffold:

تم تصنيف الدعامات البنائية الى اكثر من تصنيف منها؛ ما اشار اليه "محمد عطية خميس" إلى ثلاثة أنواع من دعامـات التعلم البنائي التى تعمل كمساعدات يحتاج إليها المتعلم داخل بيئة التعلم الإكترونى وهي: ( ) الدعامات الإجرائية، ( ) دعامات التعليم،ب) دعامات التدربب، فالدعامات الإجرائية؛ هى المساعدات المقدمة للمتعلم لتشغيل الكيان الإلكترونى والتحكم فيه وكيفية استخدامه، أما دعامات التعليم؛ فهى المساعدات الخاصة بالتعليم للحصول على معلومات تفصيلية أو عرض إنى أمثلة تفصيلية أو شرح مفهوم أو شكل، أما مساعدات التذريب؛ فهي التي تقدم بمصاحبة التدريبات والتطبيقـات البنائيـة لمسـاعدة الطـلاب في حل هذه التدريبات ويتحقق ذلك باستخدام التلميحات والإثارات "Cues/Hints"، أو الرسوم والأشكال والنمذجة، أو تقديم الأمثلة والعبارات الثارحة، أو هذه

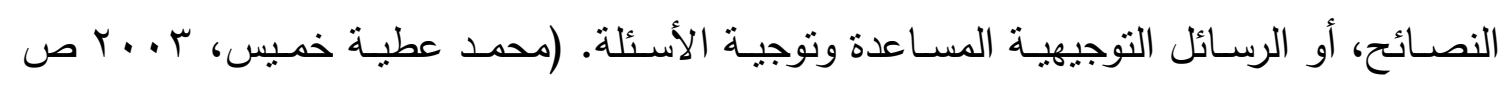

وفى دراسـة"هانافين Hannafin, M" M تحديد عدد من الدعامات البنائية منها (دعامات بنائية من النوع المفهومى، ودعامات ما وراء المعرفة، و الدعامات البنائية الإجرائية، و الدعامات البنائية الإستراتيجيه) وذلك من خلال برنامج كمبيوترى متعدد الوسائط لمساعده الطلاب على اعداد وتأليف مذكرات حربيه متعدده الوسائط: دعامات بنائية من النوع المفهومى Conceptual Scaffolding :بتم تقديم هذا النوع من 
الدعامات البنائية حينما يتم تعريف المهمة جيدا وتقوم بارشاد المستحدمين من خلال تحديد

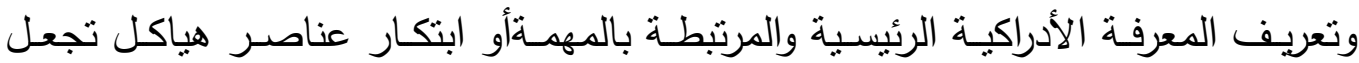

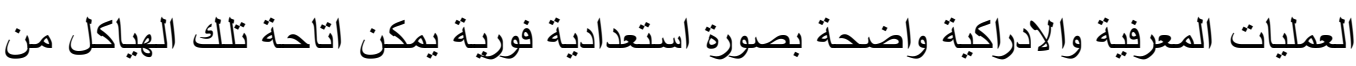

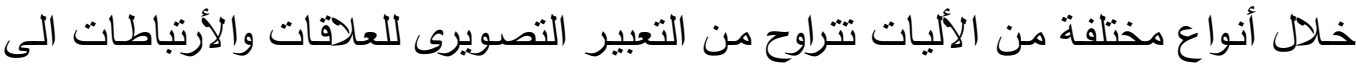

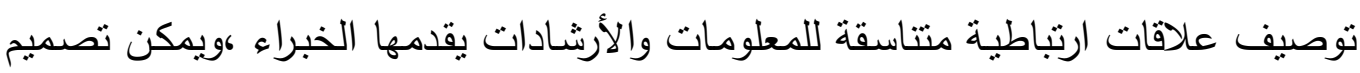
الدعامات البنائية من النوع المفهومى التصورى لمساعدة الطلاب لمناقثنة وفهم المشـاكل

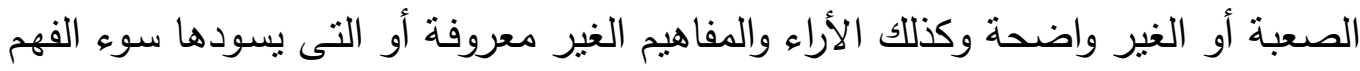

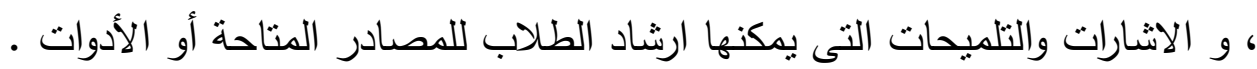

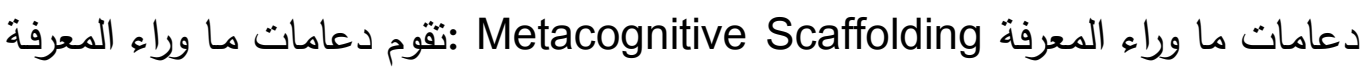

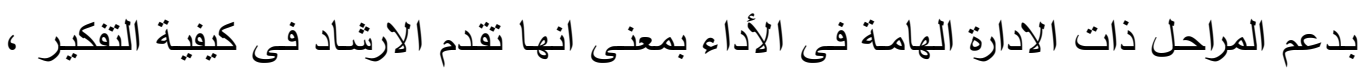

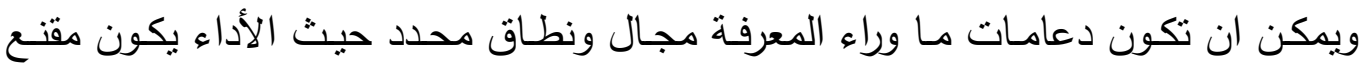

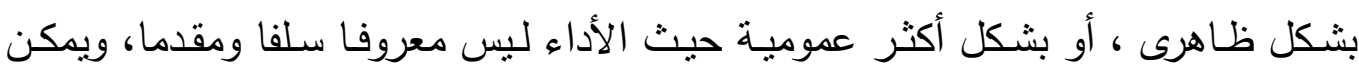
للدعامات ما وراء المعرفة أيضا ان تذكر الطلاب بالانعكاس نحو الأهداف أو يحثهم على الهى

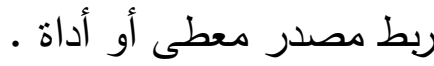

الدعامات البنائيـة الإجرائيـة Procedural Scaffolding : تشيـير الدعامات البنائيـة

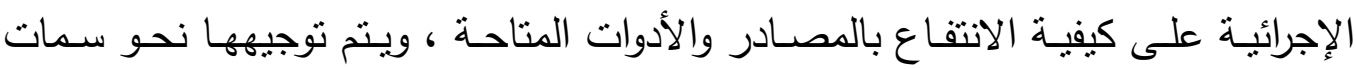

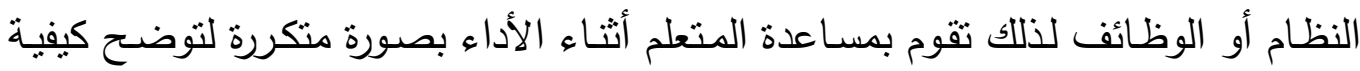

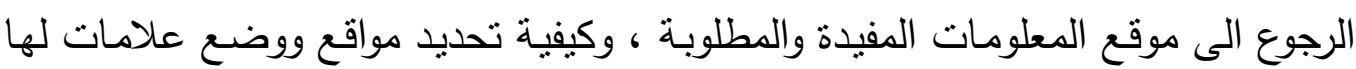
أو موارد بغرض معاينة لاحقة أو كيفية نشر أدوات معطاه .

ه Strategic Scaffolding : توضـح الدعامات البنائية الاستراتيجية التوجهات البديلـة التى يثبت فائدنها فى دعم التحليل والتخطيط والقرارات التكنيكية ، والتى تركز على تحديد وانتقاء المعلومات المرغوبة وتقييم الموارد المتاحة وربط ما هو جديد بالمعرفة والخبرات الموجودة لدى المتعلم. (Hannafin, M., 2001) 


\section{د/ أحمد حلمي محمد أبوالمجد}

تمت إجراءات البحث وفقاً للخطوات الاتية:

أولاً: إعداد التصميم التعليمى للمعالجة التجريبية للبحث:

التصميم التعليمى يلعب دور اساسى في تحديد المواصفات التعليمية لأحداث عملية التعليم

والتعلم من المعالجة التجريبية ومصادرها، وهو كعملية يتضمن تحليل وتحديد الحاجات والأهداف وخصائص المتعلمين والمحتوى التعليمي ومواصفات مصادر التعلم، وتتظيم عمليات التقييم والتقويم، بهدف ضبط وتتظيم إجراءات وعمليات التصميم والإنتاج، وتحسين جودة المنتج النهائى لمادة المعالجة التجريبية للبحث.حتى تحقق الأهداف المحددة فى ضوء المتغيرات التجربيية موضوع البحث، وفى ضوء الاطلاع على بعض نماذج التصميم التعليمي؛ نموذج محمد عطية خميس

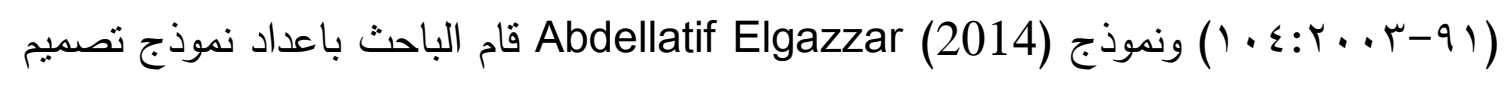
مقترح لعمل المعالجة التجريبية والذى تم وفقاً للخطوات والمراحل الاتية:

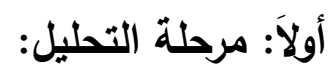

\section{- إيد الأهداف التعليمية:}

تعد عمليـة تحديد الأهداف التعليميـة وصياغتها فى صسور النواتج التعلم المرغوب فيها عملية أوليـة ضـرورية، وقد اعد الباحث قائمسة بالاهداف التعليميـة فى صـورتها المبدئيسة()، وتم

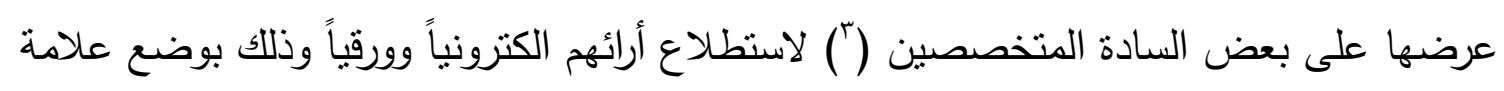
( ) فى الخانة المحدة لذلك والتي تضمنت: دقة صياغة الهدف، أهمية كل هدف، إضافة /حذف لهفئ الأهداف بما يتوافق مع موضوع البحث.

\begin{tabular}{|c|c|c|c|c|c|}
\hline المتوسط & الرابع & الثالث & الثانى & الأول & \\
\hline$\% \wedge \curlyvee$, Y० & $\% \wedge$. & $\% \wedge \varepsilon$ & $\% \wedge 4$ & $\% \wedge 0$ & نسبة رأى \\
\hline
\end{tabular}

r - ملحق ( ) قائمة الأهداف التعليمية لبعض مهارات إنتاج برامج الفيديو لاى طلاب تكنولوجيا التعليم.

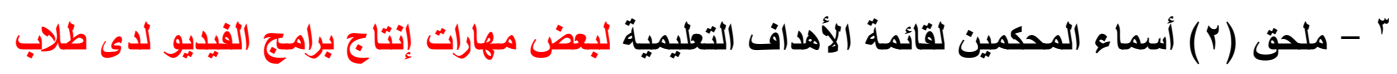
تكنولوجيا التعليم. 


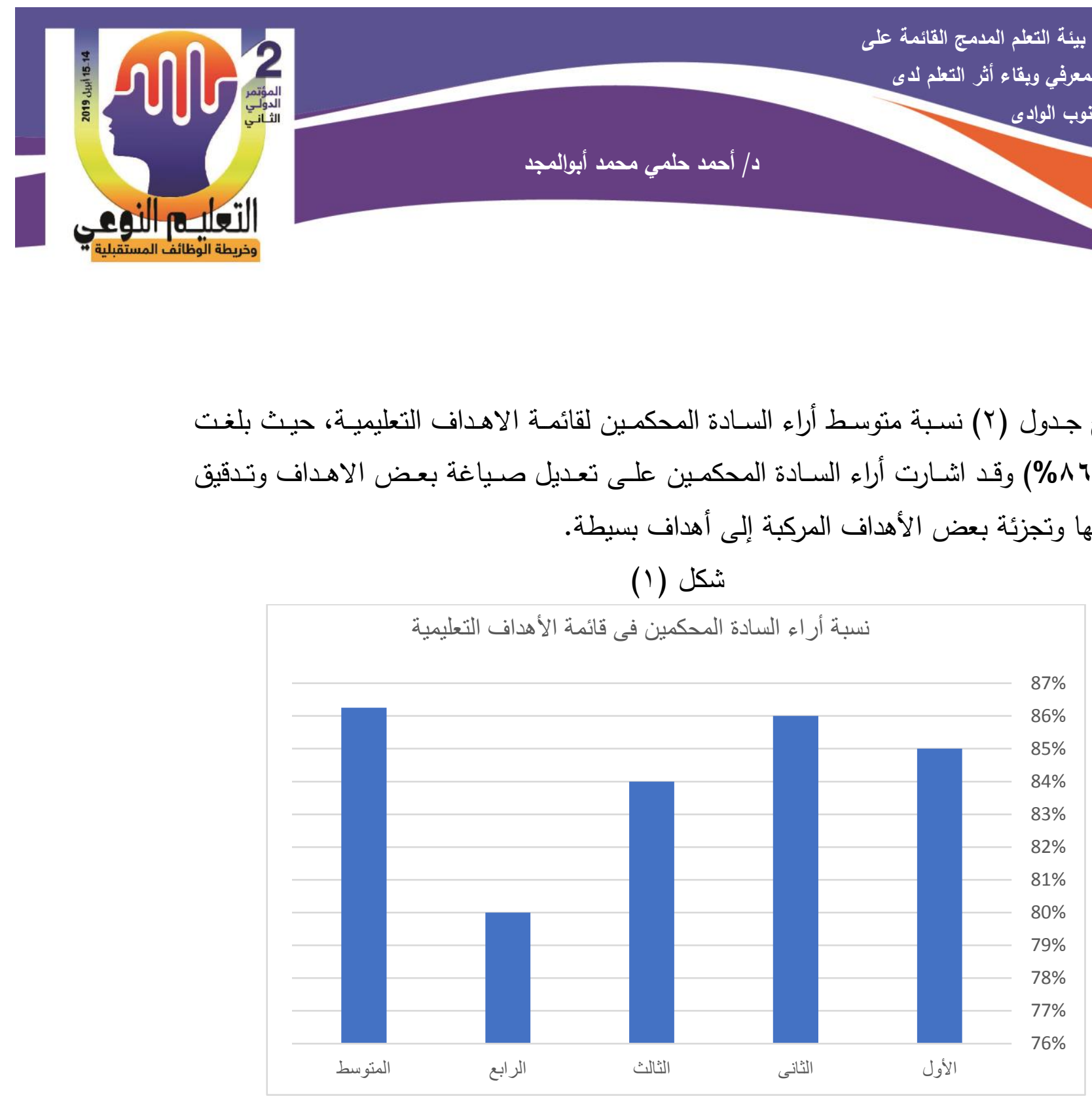

يوضـح جـول (Y) نسبة متوسـط أراء السـادة المحكمين لقائهـة الاهـداف التعليميـة، حيث بلغـت

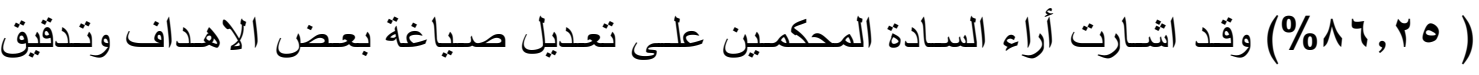
صياغتها وتجزئة بعض الأهداف المركبة إلى أهداف بسيطة.

شكل (1)

وقد قام الباحث باعداد قائمة الاهداف التعليمية فى صورتها النهائية(؛) كما يلى : - مهارة استخدام كاميرا الفيديو • ويتقرع من هذا الهدف الأهداف الفرعية التالية:

- يتعرف على خصائص كاميرا الفيديو -

- يتعرف على أنواع كاميرات الفيديو .

- تحديد الأجزاء الرئيسة لكاميرا الفيديو.

- تهيئة كاميرا الفيديو للاستخدام.

\section{r - تحديد المحتوى العلمى:}

تم اختيار مهارة استخدام كاميرا الفيديو كمهارة رئيسية تتفرع منها عدة مهارات فرعية كمحتوى علمى لمادة المعالجة التجريبة فى ضوء الاستفادة من خبرة الباحث الذى يقوم بتدريس

؛ - ملحق (r) قائمة الأهداف التعليمية النهائية لبعض مهارات إنتاج برامج الفيايو لاى طلاب تكنولوجيا

\section{التعليم.}

مجلة البحوث في مجالات التربية النوعية ماية

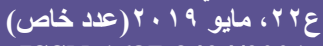
ISSN-1687-3424/2001
253 
مقرر انتاج برامج الفيديو والتليفزيون لطلاب قسم تكنولوجيا التعليم، بالإضافة لرجوع الى العديد من

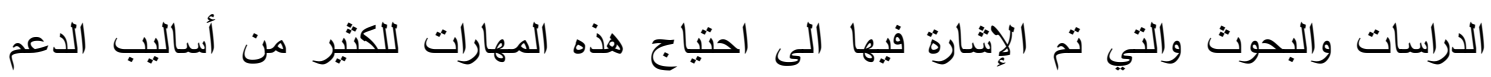
والتعزيز للتعامل معها وتعلم خطواتها، و روعي عند تحديد هذه المهارة الاعتبارات التالية :-

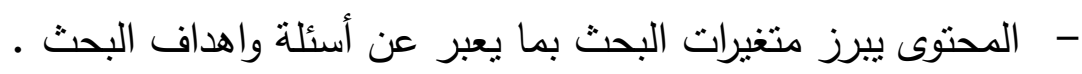
- - - هذه المهارات يجد المتعلمين صعوبة فى فهمها وأدائها. - - مناسبة المحتوى للعرض فى مادة المعالجة التجريبية ( الفصول المعكوسة).

\section{r- تحليل خصائص المتعمين:}

وفى هذه الخطوة يتم التعرف على خصائص المتعلمين عينة البحث و الموجه إليهم مادة المعالجة التجريبية ومحاولة تحديد الجوانب المعرفية، المهارية، الوجدانية وكذلك أعمارهم الزمنية،

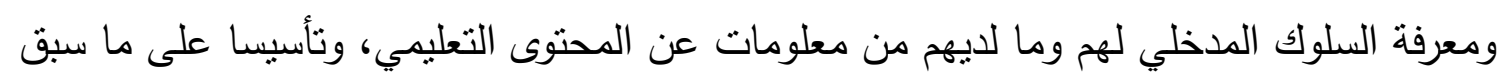
تم تحديد هذه الخصائص على النحو التالى: - - جميع المتعلمين من طلاب كلية التربية النوعية قسم تكنولوجيا التعليم. -

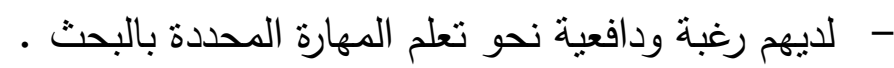

\section{ثانياً: مرحلة تصميم وإنتاج المعالجة التجريبية:}

تتعلق هذه المرحلة بتوصيف ورسم المبادئ النظرية والإجراءات المتعلقة بالتعلم من بيئة

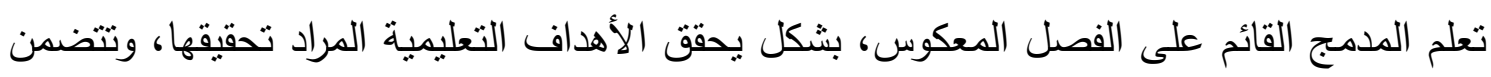

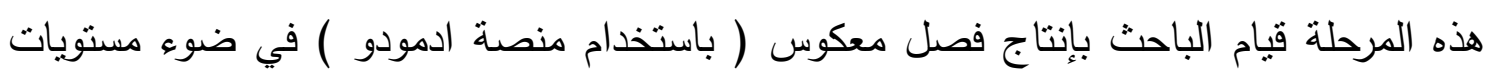

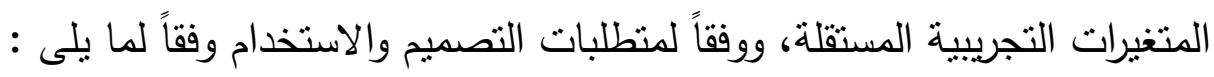

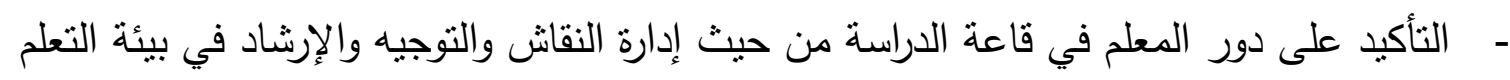

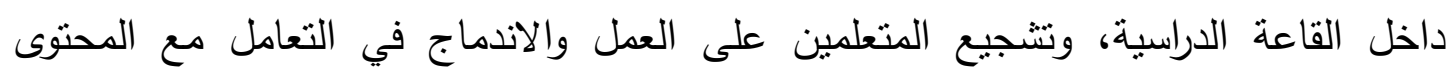
الالكتروني المقدم عبر الفصل المعكوس بنمطيه.

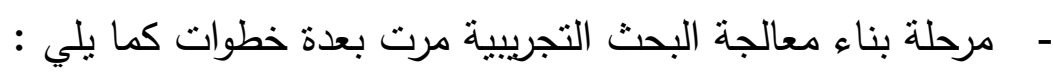

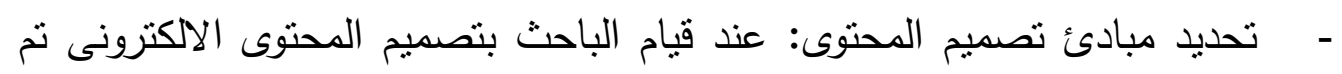

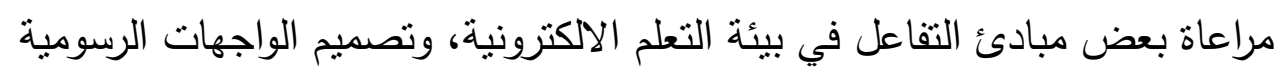

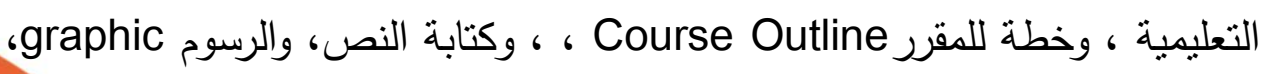




\section{د/ أحمد طلي محمد أبوالمجد}

\section{طلاب تكنولوجيا التعليم بجامعة جنوب الثوادى}

والفيديو Video ، والصوت Sound والارتباطات Sinks ، وغرف الحوار المباشر، ومنتديات المناقشة، البربد الإكتروني والتي ساعدت على تقديم الدعم وفق نمطيه

$$
\text { في التصميم التجريبى للبحث. }
$$

- تصميم الواجهة الرئيسة: و هى عبارة عن صفحة البداية التى تظهر للمستخدم، و

يتم تحميلها بمجرد كتابة عنوان الموقع و تحتوى هذه الصفحة اسم المقرر، و الجهة المسئولة عن عرضده، و يتم من خلالها ادخال اسم المستخدم وكلمة المرور للاخول

على النمط والتعامل معه للمتعلمين فى المجموعة المخصصة لهذا النمط. - صفحة المقرر : تقدم وصفا تقصيليا لمكونات المقرر من حيث أهدافه، والمتطلبات

اللازمة لدراسة المقرر ومحتوياته والتقويم.

- صفحة الأخبار : تقدم بعض الأخبار العامة المرتبطة المقرر •

- صفحة إدخال البيانات الثخصية: حيث لكل طالب له رقم دخول وكلمة مرور

وبمجرد كتابة رقم الدخول وكلمة المرور يستطيع المتعلم الدخول إلى المحتوى.

ثالثاً: مرحلة التقويم والتطوير:

وتضمنت هذه المرحلة التجريب الأولي للتأكد من صلاحيتها وإجراء التعديلات وفحص

ادائها التعليمي وكفاءتها التقنية والمنهجية وتم إجراء التعديلات المقترحة واصبحت البيئة التعليمية جاهزة وفقاً للتصميم المقترح للبحث. ثانياً إعداد أدوات البحث: الاختبار التحصيلى: - إنى

تعتبر الاختبارات من اهم وسـئل جمع البيانات، وبستخدمها الباحثون على نطاق واسع في المجالات المختلفة للبحوث، فهى تعمل على جمع البيانات وإعطاء وصافاً كمية بدقة وموضوعية اذا مـا احسن اعداد وصياغة بنوده (مصطفى حسين، فاتن زكريا، ع . . ץ، 00) وقد فى ضـوء الاعتبارات السابقة تم بناء الاختبار التحصيلى الموضوعى ووفقا للخطوات الآتية: 1 - الهدف من الاختبار:

تم بناء اختبار تحصيلى موضـوعى من نـوع الاختيار من متعدد يهدف إلى قياس اثر التحصيل المعرفى المرتبط ببعض مهارات إنتاج برامج الفيديو التعليمية. 



\section{د/ أحمد حلمي محمد أبوالمجد}

צ- إعداد الصورة الأولية للاختبار:

تم إعـداد الصـورة الأوليـة للاختبـار وعرضـها على المحكمين وذلـك لاسـتطلاع رأيهـم فيمـا يلى (ه):-

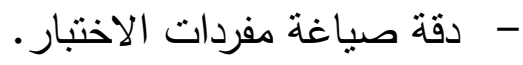

- مدى تحقيق مفردات الاختبار للأهداف التعليمية.

- - وضوح الأشكال التوضيحية.

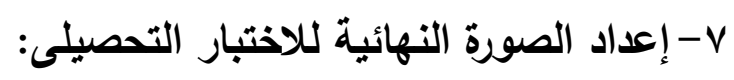

قام الباحث بتعديل صياغة بعض مفردات الاختبار ، وكذلك إعادة تصميم بعض البدائل فى

ضوء ما اتفق عليه المحكمين، تم اعداد الاختبار فى صورته النهائية (؟) .

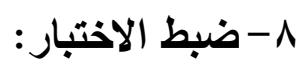

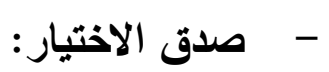

نظرا لأهمية قياس صدق الاختبار واعتبار قياسه شرطاً اساسياً للتأكد من صـلاحية الاختبار

للتطبيق وقياس ما وضع لقياسه وتحقيق ما صمم من اجله، حيث يحدد قيمة الاختبار وصلاحيته ،

وقد تم فى نطاق البحث حساب صدق الاختبار بطريقتين هما: -

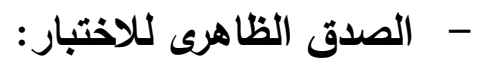

الصدق الظاهري Face Validity أحد أنواع الصدق الوصفي Descriptive Validity، حيث يحدد مدى مناسبة الاختبار لما وضـع من اجله بالفحص المبدئي لمحتوى الاختبار ومطابقة ذلك بالوظيفة السلوكية التى يهدف الاختبار إلى قياسها، فإذا بدا أن فقراته ترتبط ظاهريا بالوظيفة التى يهدف إلى قياسـها كان ذلك دليلا على أن الاختبـار صـادق صـدقا ظاهربـاً (على مـاهر

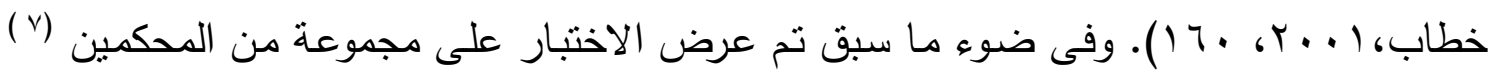
لابداء الراى في محتوى الاختبار في ضوء الأهداف المراد تحقيقها.

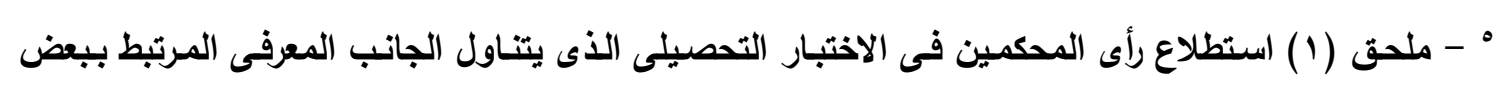
مهارات إنتاج برامج الفيليو التفاعلية لاى طلاب تكنولوجيا التعليم.

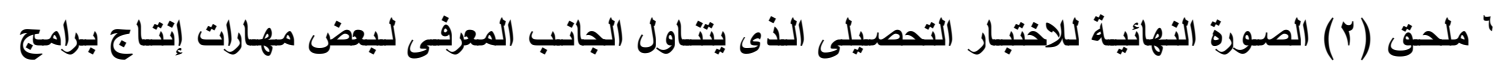

v- ملحق (1) أسماء المحكمين للاختبار التحصيلى الموضوعى . 



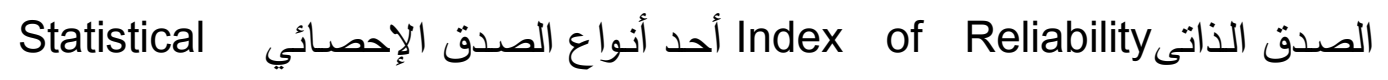

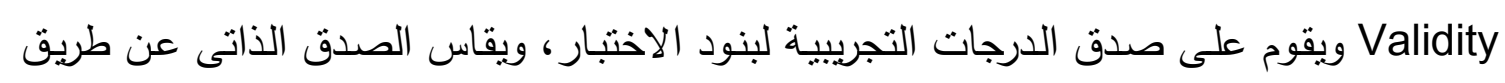

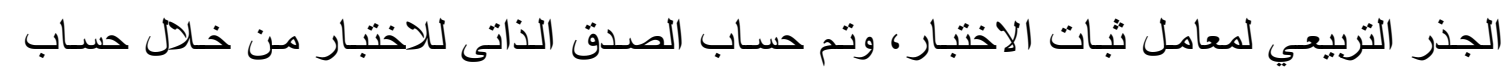

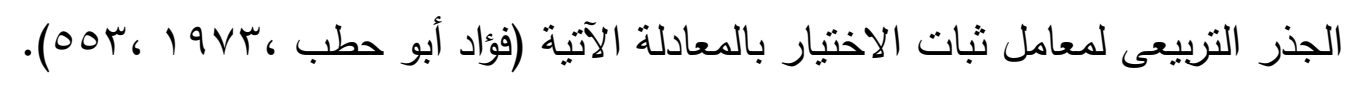

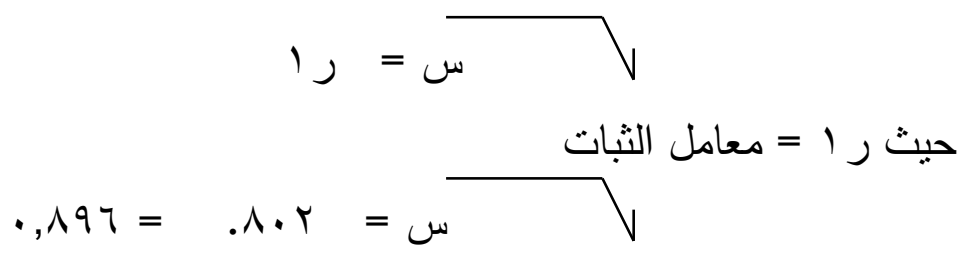

وبحساب الصدق الذاتى وجدا أن معامل الصدق الذاتى مساوياً (197, · ) وتعد هذه قيمة دالة على أن الاختيار على درجة مناسبة من الصدق.

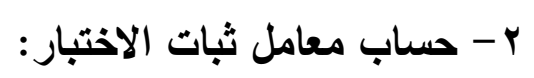

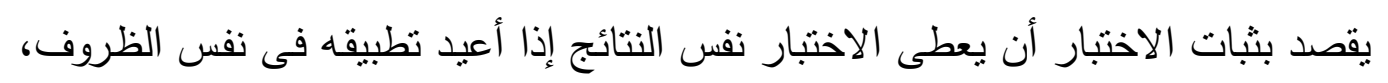

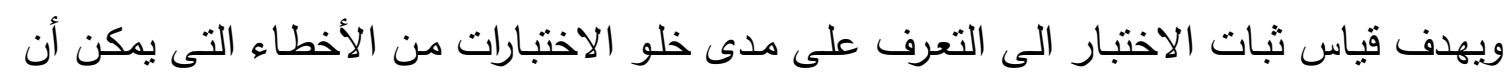

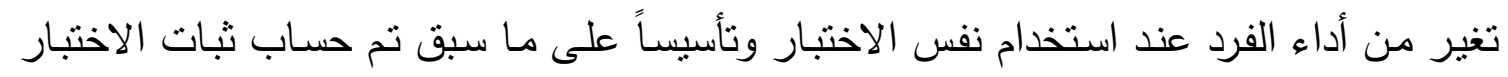

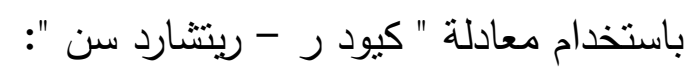

$$
\left(a^{-}\right)+2 \varepsilon x
$$

$2 \varepsilon(1-\dot{1})$

$$
\begin{aligned}
& \text { ر = معامل الثبات } \\
& \text { ن ع = التباين } \\
& \text { ن = عدد الأسئلة فى الاختبار }
\end{aligned}
$$

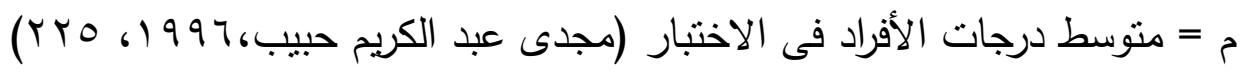

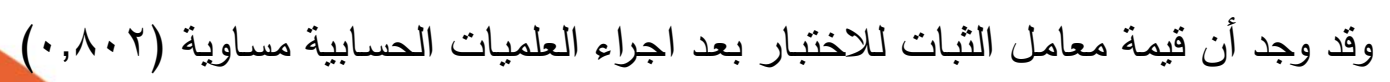


مما يدل على أن الاختبار على درجة مرتفعة من الثبات. 1- حساب معمل السهولة والصعوية للاختبار: تم حسـاب معـاملات السـهولة والصـعوبة لمفردات الاختبار التحصيلى باستخدام المعـادلات

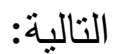

عدد الطلاب الذين أجابوا إجابة صحيحة معامل السهولة =

عدد الطلاب الذين حاولوا الإجابة معامل الصعوبة = 1- معامل السهولة

وقد تراوحت معاملات السهولة ومعاملات الصعوبة لدفردات أسئلة الاختبار التحصيلى (^) من

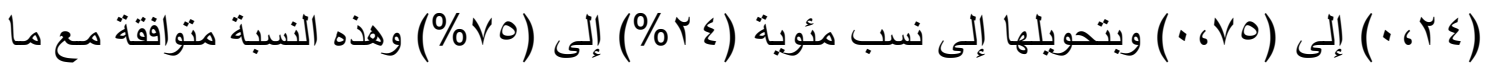

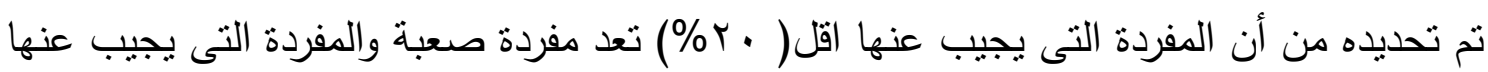

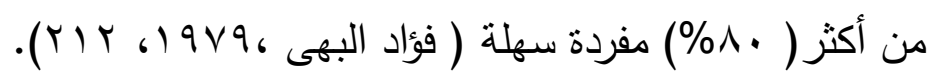

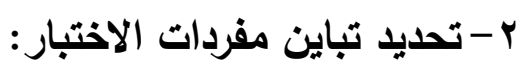

نم حساب قدرة أسئلة الاختبار على التباين باستخدام المعادلة التالية:

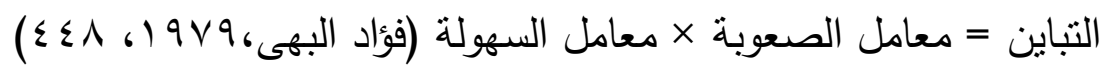

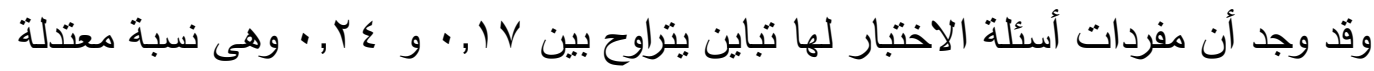

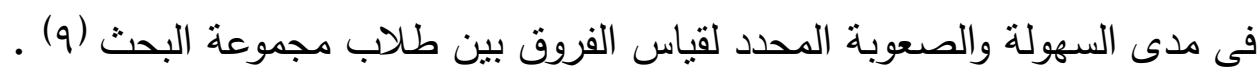
r- حساب معامل السهولة المصحح من أثر التخمين لمفردات الاختبار:

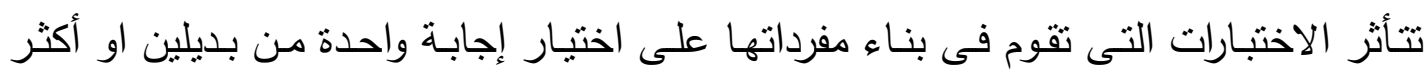

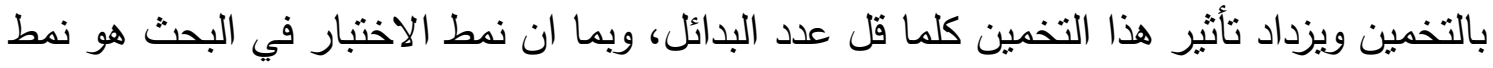
الاختيار من متعدد فان حساب معامل السهولة المصحح من اثر التخمين لدفردات الاختبار يؤدى لأدي الى قوة الاختبار ومفرداته و لحساب المعامل تم استخدام المعادلة الآتية:

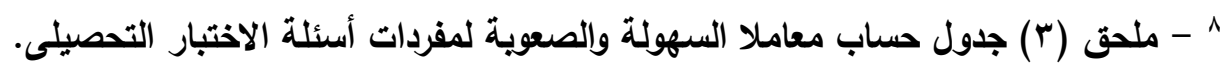

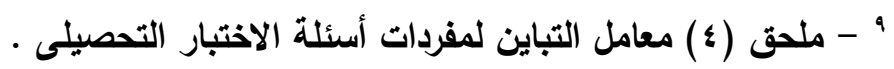



روعى عند تقدير درجات مفردات الاختبار أن تعطى الإجابات الصـحيحة درجة (واحدة) والإجابة الخطأ (صفر) وعلى ذلك اصبحت الدرجة الكلية للاختبار (Y0) درجة وقد ثم إعداد مفتاح للتصحيح لضمان الدقة واختصار الوقت عند التصحيح. ثالثاً: إجراء التجربة الإستطلاعية: تثضمن إجراءات التجربة الاستطلاعية ما يلي: ا. تحديد مكان التجربة الاستطلاعية كلية التربية النوعية بقنا قسم تكنولوجيا التعليم وتم تحديد وشرح الضوابط الاولية لعملية التعلم من المعالجة التجريبية والاجراءات الضبطية الخاصة بالبحث ومعالجتة التجريبية، وروعي ان يكون الاتصال والتعلم بشكل حر من اى مكان ودون التقبد بالمعمل او الكلية. r. اختيار (· () من طلاب الفرقة الرابعة تكنولوجيا التعليم تم إجراء التجربة الإستطلاعية عليهم. r. تم تطبيق أدوات البحث قبليأ على العينة الاستطلاعية للبحث. ع. إجراء التجربة الإستطلاعية حيث تم تقسيم (· (1) الطلاب إلى مجموعتين تبعا للتصميم التجريبي للبحث و المعالجة التجريبية والاجراءات الضبطية الخاصة بالبحث . 0. تطبيق أدوات البحث بعدياً على العينة الاستطلاعية للبحث. 7. وقد أفادت التجربة الاسنطلاعية فى رصد بعض المشكلات وعدم قدرة بعض الطلاب على استيعاب هذه المشكلات والتعامل معها أهمها (ضعف البنية التحنية - عدم استيعاب بعض

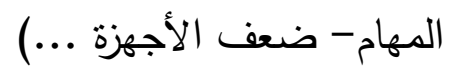
V. إجراء التعديلات فى ضوء نتائج التجربة الاستطلاعية. خامساً: إجراء التجرية الأساسية للبحث: تثضمن: ا. شرح ضوابط عملية التعلم من المعالجة التجريبية والاجراءات الضبطية الخاصة بالبحث ومعالجته التجربيية ومراعاة السلبيات التى ظهرت فى التجربة الاستطلاعية وتم تسجيله في بي 
شكل مقطع فيديو - (1)

r. تحديد امكان بديلة للاعتماد عليها على (معمل الحاسب الالى بالقسم) في غير مواعيد

$$
\text { وجداول الدراسة. }
$$

r. تقسيم عينة البحث إلى مجموعتين، مجموعة تجريبية أولى (Yo) تستخدم المعالجة التجريبية الأولى القائم على الدعامات الموجزة، ومجموعة تجريبية ثانية (Yo) تستخدم المعالجة

التجربيية الثانية القائم على الدعامات التفصيلية.

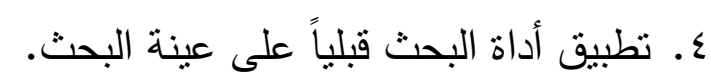

هـ تطبيق المعالجة التجربيية وفقاً للتصميم التجربيي للبحث والتي استغرقت اسبوعين. 7 ـ تطبيق أداة البحث بعدياً على عينة البحث الحصول على نتائج التطبيق. V. الحصول على نتائج التطبيق تمهيداً لمعالجتها احصائياً.

$$
\text { نتائج البحث: }
$$

تم معالجة البيانات التي تم جمعها من نتائج الاختبار التحصيلى القبلي والبعدي، وزمن

التعلم لكل طالب، إحصائياً باستخدام برنامج المعالجة الاحصائية SPSSاصدار بr كما يلي:

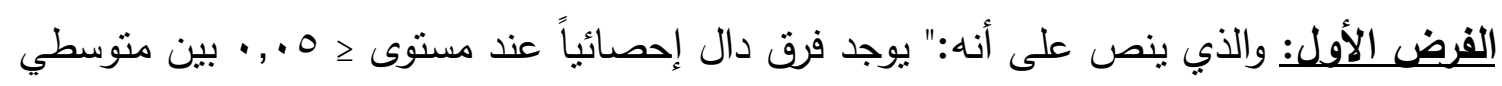
درجات الطبيق القبلى والبعدى طلاب المجموعة التجريبية الأولى في التحصيل المعرفي المرتبط بمهارات انتاج برامج الفيديو والتلفزيون التعليمية لصالح التطبيق البعدى يمكن ارجاع أثره لاستخدام

الفصول المعكوسة القائمة على الدعامات."

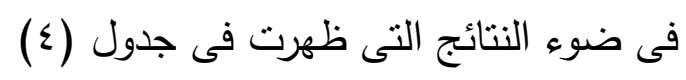

المتوسطات والأنحراف المعيارى فى نتيجة التحصيل المعرفى المرتبط بالاختبار التحصيلى القبلى جلى

\begin{tabular}{|c|c|c|c|c|c|}
\hline الحصائية & درجة الحرية & قيمة"ف" المحسوية & الأنحراف & الحستوسط & \\
\hline عند مستوى إحصائيا & 1 & $\cdot, 7$ & $7,7 V$ & $r \cdot, r$. & التطبيق القبلى \\
\hline 6.0 & 1 & $\cdot, V Y$ & $V, r$. & $r V, O r$ & التطبيق البعدى \\
\hline
\end{tabular}
والبعدى لمجموعتى البحث التجريبية الاولى 


\section{Nô" \\ التعلمبـام اللنوعي}

د/ أحمد حلي محمد أبوالمجد

يتضح من الجدول السابق وجود فرق ذات دلاله إحصائياً عند مستوى (0., •) بين متوسطي درجات الاختبار التحصيلى القبلى والبعدى للمجموعة التجربيية الاولى يمكن ارجاع اثرة الى استخدام الفصل المعكوس في بيئة التعلم الاكترونية وهذا ما شارث اليه البحوث والدراسات التي تم الرجوع اليها في الاطار النظرى للبحث ، وتظهر هذه الفروق في الثكل (r) شكل (r)

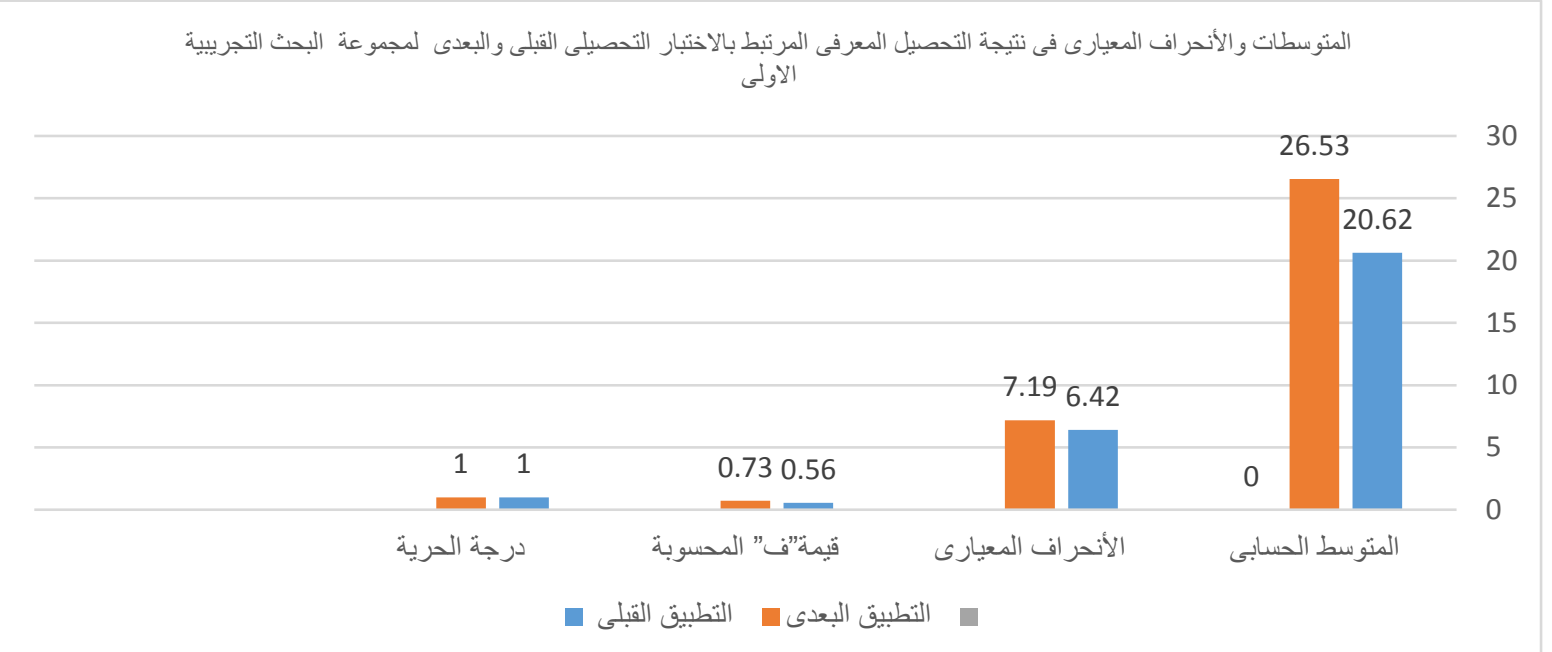

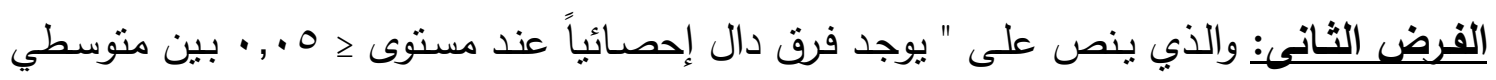
درجات التطبيق القبلى والبعدى لطلاب المجموعة التجريبية الثانية في التحصيل المعرفي المرتبط بمهارات انتاج برامج الفيديو والتلفزيون التعليمية لصالح التطبيق البعدى يمكن ارجاع أثره لاستخدام الفصول المعكوسة القائمة على الدعامات. فى ضوء النتائج التى ظهرت فى جدول (0) المتوسطات والأنحراف المعيارى فى نتيجة التحصيل المعرفى المرتبط بالاختبار التحصيلى القبلى والبعدى لمجموعة البحث التجريبية الثانية

\begin{tabular}{|c|c|c|c|c|c|}
\hline الدصائية & درجة الحرية & قالمحسوية" & الأنحراف & المستوسط & \\
\hline \multirow{2}{*}{ عند مستوى إحصائيا } & 1 & $\cdot, 07$ & $T, \varepsilon Y$ & $r \cdot, 7 r$ & التطبيق القبلى \\
\hline & 1 & $\cdot, \mathrm{VT}$ & $v, 19$ & rT,OT & التطبيق البعدى \\
\hline
\end{tabular}




\section{د/ أحمد حلمي محمد أبوالمجد}

\section{التعلهم:النوعي}

\section{وخريطة الثوظائف المسنقبلية التصي}

يتضح من الجدول السابق وجود فرق ذات دلاله إحصائياً عند مستوى (0., •) بين متوسطي درجات الاختبار التحصيلى القبلى والبعدى لمجموعة البحث التجريبية الثانية يمكن ارجاع اثرة الى استخدام الفصل المعكوس في بيئة التعلم الالكترونية وهذا ما شارت اليه البحوث والدراسات التي تم الرجوع اليها في الاطار النظرى للبحث ، وتظهر هذه الفروق في الثكل (ع).

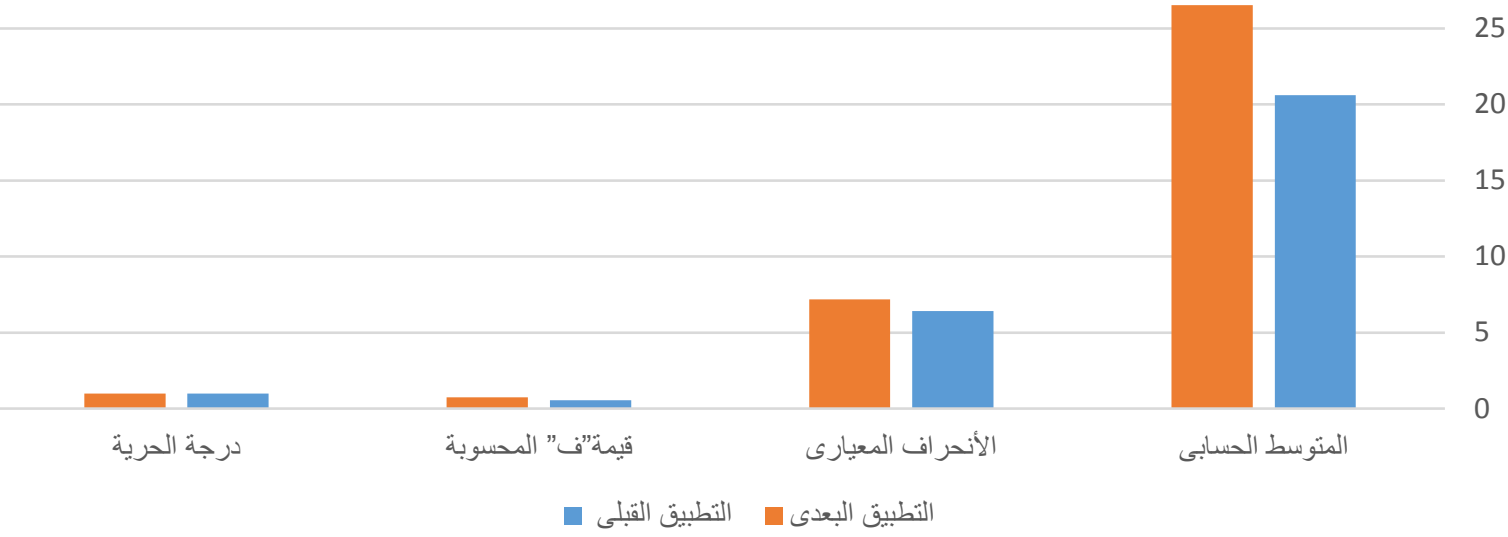

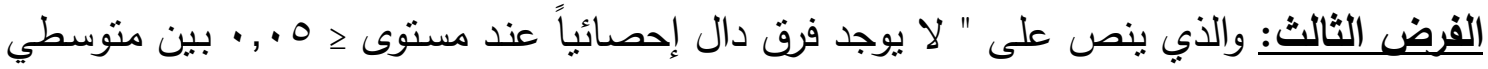
درجات التطبيـق البعدى لطـلاب المجموعتين التجربييتين الأولى والثانيـة في التحصبل المعرفي المرتبط بمهارات انتاج برامج الفيديو والتلفزيون التعليمية عند استخدام الفصـول المعكوسـة يمكن ارجاع الأثز الأساسي لها لنمط الدعامات" فى ضوء النتائج التى ظهرت فى جدول (T) المتوسطات والأنحراف المعيارى فى الاختبار التحصيلي المعرفى لمجموعتى البحث الاولى والثانية

\begin{tabular}{|c|c|c|c|c|c|}
\hline الحصائية & درجة الحرية & قيمة"ق" & الأنحراف & الحسبابى & المجموعة \\
\hline غيردائيا عند & 1 & . Or & V, & YO, YT & لتجريبية الأولى \\
\hline مستوى 0 .، & 1 &., 07 & $9,$. & $r \leqslant, \leqslant 0$ & التجريبية الثانية \\
\hline
\end{tabular}




\subsection{0 \\ التعليـنام النوعي}

د/ أحمد حلمي محمد أبوالمجد

يتضح من الجدول السابق عدم وجود فرق دال إحصائياً عند مستوى (0., •) بين متوسطي درجات التحصيل نتيجة لاستخدام نمط الدعامات فى بيئة التعلم الاككترونية المعكوسة، ويمكن ارجاع هذه النتيجة إلى أن متغير نمط الدعامات المستخدم فى بيئة التعلم عمل كمثير لعملية التعلم واعتبرت الدعامات هنا جزء رئيسي من بيئة التعلم وليس تعزيز لها، وهو ما أدى إلى إهى ظهور تقارب في نتائج المعالجات المقدمة والتي أظهرت عدم وجود فروق دالة إحصائياً يمكن ارجاعه إلى نمط الدعامات البنائية. ويمكن توضيح ذلك في الثكل (0). المتوسطات والأنحر اف المعيارى فى الاختبار التحصبلي المعر فى لمجمو عتى البحث الاولى و الثانية

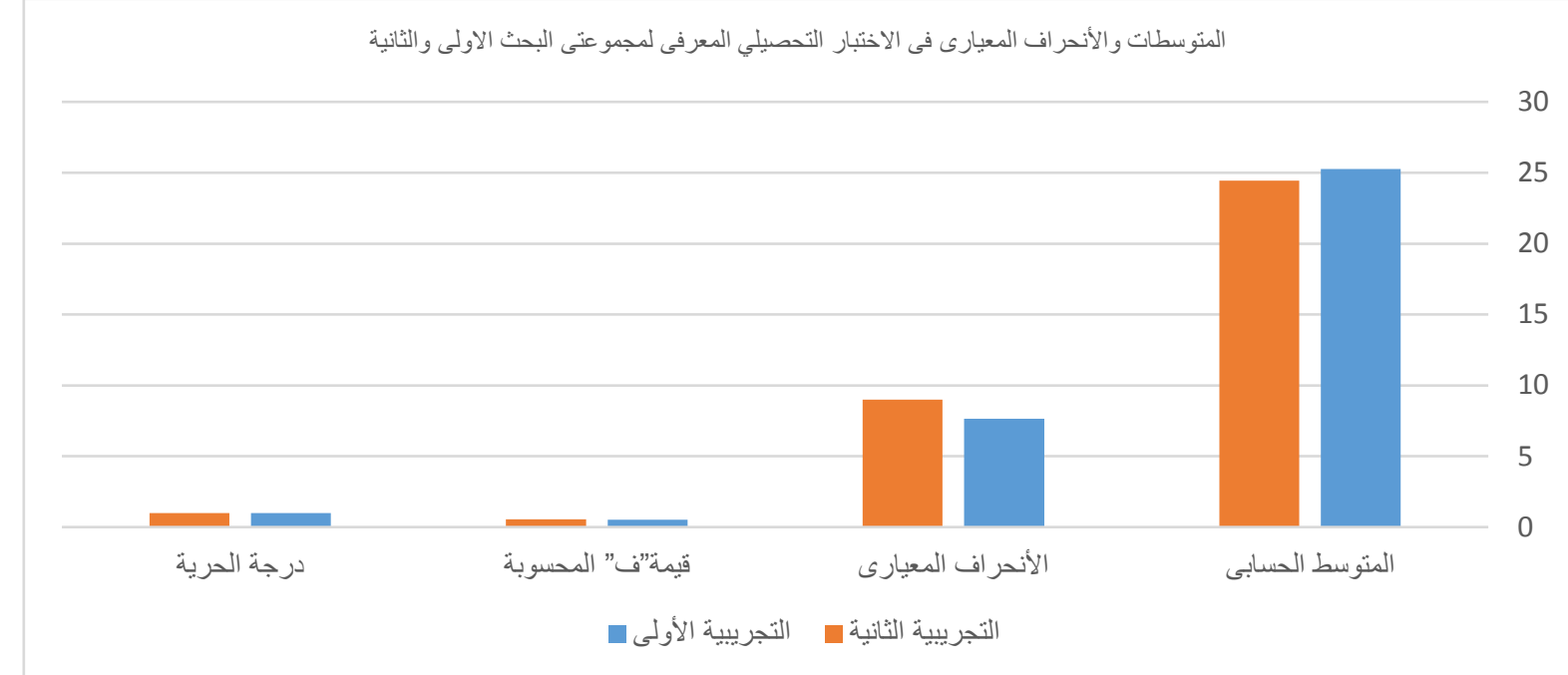

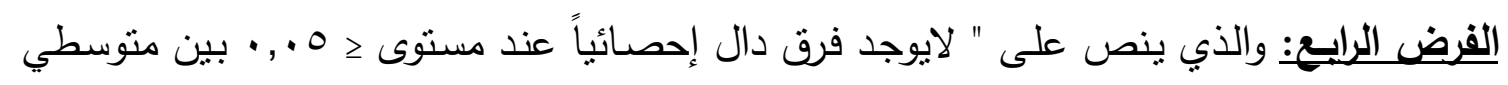
درجات طلاب المجموعتين التجريبيتين الأولى والثانيـة في بقاء اثر التعلم لمهارات انتاج برامج الفيديو والتلفزيون التعليمية عند استخدام الفصول المعكوسة يرجع للأثر فيه الى لنمط الدعامات" فى ضوء النتائج التى ظهرت فى جدول ( V ) المتوسطات والأنحراف المعبارى لمجموعتى البحث الاولى والثانية المرتبط بالاختبار التحصيلى البعدى لحساب كفاءة التعلم

\begin{tabular}{|c|c|c|c|c|c|}
\hline الحصائية & درجة الحرية & قيمة"ف" المحسوية & الأنحراف & الحسابى المتوسط & المجموعة \\
\hline إحصائيا عند الح & 1 & $\cdot, 90$ & $1,1 \varepsilon$ & $\cdot, 049$ & التجريبية الأولى \\
\hline مستوى 0 .، & 1 & $\cdot, 19$ & $1, r \leq$ & $\cdot, \varepsilon \wedge r$ & التجريبية الثانية \\
\hline
\end{tabular}




\section{OOO?

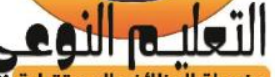

\section{د/ أحمد حلي محمد أبوالمجد}

يتضح من الجدول السابق قبول الفرض لعدم وجود فرق دال إحصائياً عند مستوى (0., •) بين متوسطي درجات التحصيل فى حساب كفاءة التعلم، ويرجع الباحث هذه النتيجة إلى أن متغير نمطى الدعامات البنائية المستخدم فى بيئة التعلم عبر الفصل المعكوس في المعالجات التجريبية عمل كمثير لجذب أنتباه الطلاب دون ان يلتفت الطلاب لنمطه ونوعه، وهو ما أدى الى عدم تأثير نمط الدعامة وذللك فيما يتعلق بالتحصيل الدراسي مما أدى إلى إختزال زمن التعلم واظهاره بشكل منكافئ مما أنعكس على حساب كفاءة التعلم، وهذا ما أدى إلى تسأوي تأثنر النمطين في المعالجات المقدمة والذى أشار الى عدم وجود فروق دالة إحصائياً قد ترجع إلى نمط دعامات وهذا

ما يوضحه شكل ( آن)

شكل (T)

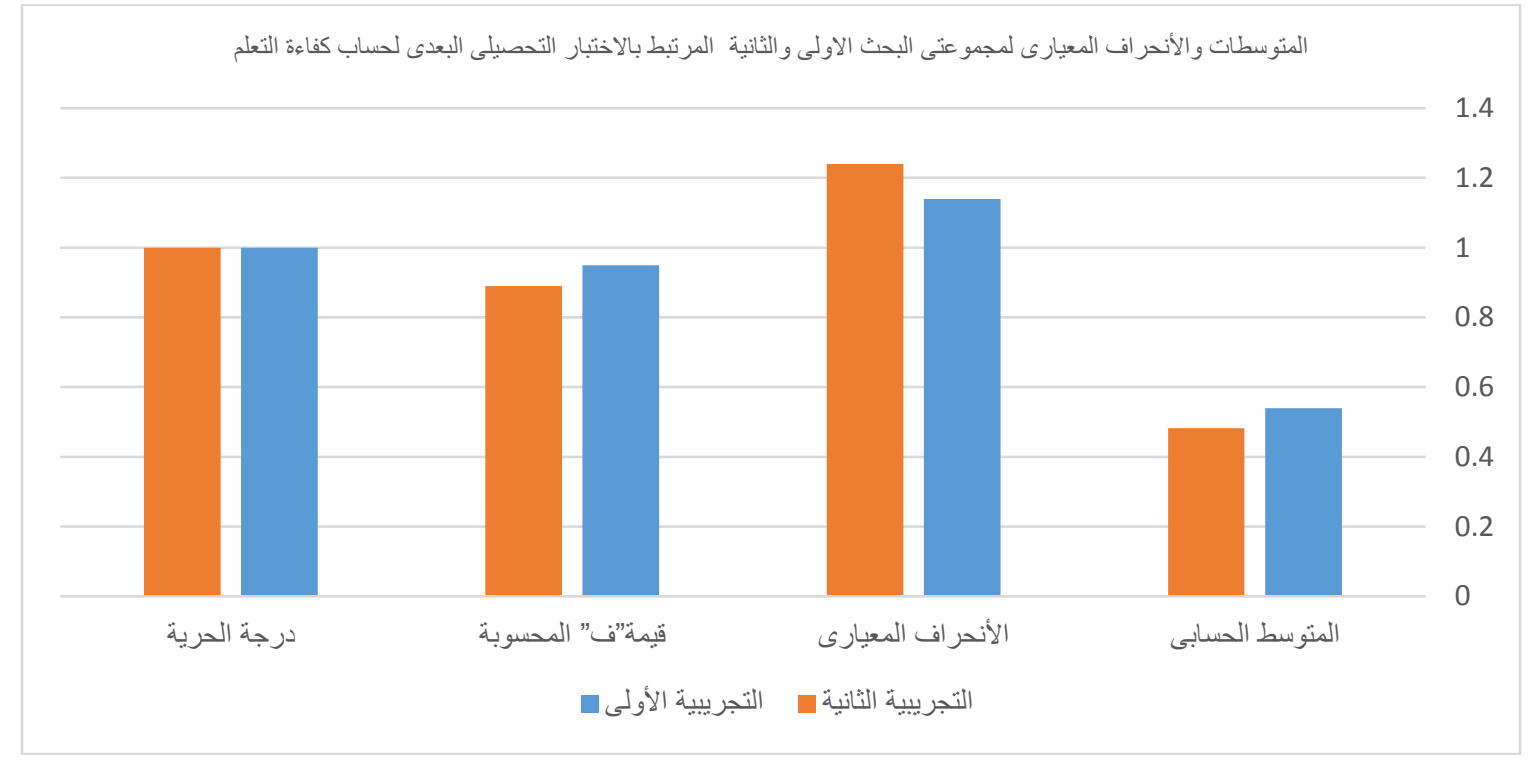

\section{التوصيات والمقترحات:}

في ضوء ما أسفرت عنه نتائج البحث يمكن تحديد التوصيات التالية: - - ضرورة الإهتمام بتصميم دعامات التعلم بأثكال وانماط منتوعة غير معقدة يمكن للمتعلمين استيعابها و الاستفادة منها ضمن بيئات تعليمية عبر الوبب. - دعوة الباحثين لاجراء مزيد من الدراسات والأبحاث التي تنتاول تقديم الدعم الالكتروني.

- إجراء دراسات حول تأثير تصميم أساليب تقديم الدعم الالكتروني في البيئات البئ 
الافتراضية التعليمية.

- ضرورة الاهتمام بتصميم بيئات الفصول المعكوسة باعتبارها مصادر تعليمية تربط بين

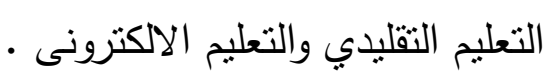

\section{المراجع : (1)

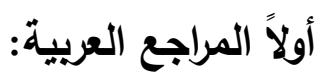

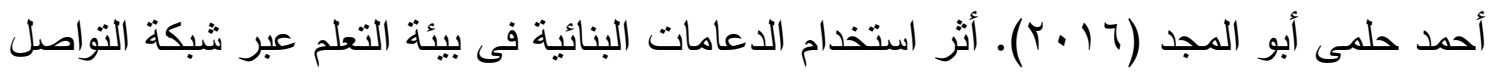
الاجتماعي (facebook) على التحصيل المعرفى وكفاءة التعلم لدى طلاب تكنولوجيا التعليم بكلية التربية النوعية جامعة جنوب الوادى. مجلة العلوم التربوية والنفسية - كلية التربية جامعة سوهاج،

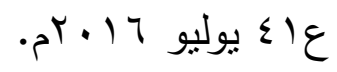
أسامه سعيد هنداوى (0 . . ץ). فاعلية برنامج مقتزح قائم على الوسائط الفائقة في تتميه مهارات طلاب شعبه نكنولوجيا التعليم وتفكيرهم الابتكاري في التطبيقات التعليمية للإنترنت، رسالة دكتوراه، كليه التربية ، جامعه الأزهر. حسن الباتع محمد عبد العاطي(T ( + ( ). معايير دعم الأداء في بيئة التعلم الإكتروني عبر

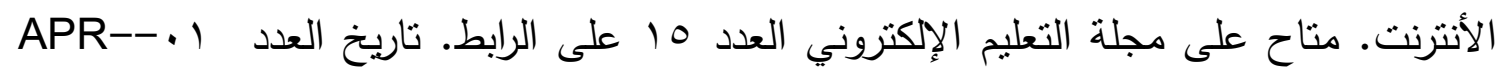

http://emag. mans.edu.eg/index.php?page=news\&task=show\&id=490 حنان بنت اسعد الزبن (10 ب ب) أثز استخدام استراتيجية التعلم المقلوب في التحصيل الأكاديمي لطالبات كلية التربية بجامعة الأميرة نورة بنت عبد الرحمن، المجلة الدولية التربوية المتخصصة،

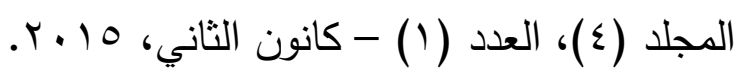

رمزية الغريب (799 99 ). التقويم والقياس النفسى والتربوى ، القاهرة : مكتبة الانجلو المصرية. زينب محمد أمين ( . . . r). إثكاليات حول تكنولوجيا التعليم. المنيا: دار الهدى للنشر والتوزيع. شاهيناز محمود أحمد (Y. . . (Y). فعالية توظيف سقالات التعلم ببرامج التعلم القائم على الكمبيوتر في تتميه مهارات الكتابة الإلكترونية لاى طالبات معلمات اللغة الإنجليزية، رسالة دكتوراه غير منشوره، كليه البنات، جامعه عين شمس. الطيب احمد حسن هارون ومحمد عمر موسي سرحان (10 r) فاعلية نموذج التعلم المقلوب في 
التحصيل والأداء لمهارات التعلم الإكتروني لدي طلاب البكالوريوس بكلية التربية، المؤتمر الدولي الأول لكلية التربية " التربية أفاق مستقبلية " في الفترة من ب I - 10 ابريل 10 ـ ب بمركز الملك عبد العزبز الحضاري. عبد العزيز بن سعيد بن يحيى آل معدي (10 ب r) فاعلية استخدام التعلم المدمج بالفصول المقلوبة في تتمية مهارات التفكير الرياضي لطلاب الصف الخامس الابتدائي، رسالة ماجستير غير منشورة، كلية العلوم الاجتماعية -جامعة الامام محمد بن سعود الإسلامية. عبد القادر محمد عبد القادر (r ( ب). دراسة التفاعل بين السقالات التعليمية ومستويات التحصيل على مهارات التفكير الرياضى والاتجاه نحو المادة لدي طلاب الصف الخامس الأساسي، دراسات عربية فى التربية وعلم النفس. العدد الثالث والاربعون، الجزء الأول. على ماهر خطاب (1 (. ب).القياس والتقويم فى العلوم النفسية والتربوية والاجتماعية ، القاهرة : مكتبة الانجلو المصرية ، المكتبة الأكاديمية، الطبعة الثانية. فؤاد أبو حطب (بVا9 ()). القدرات العقلية، القاهرة: مكتبة الانجلو المصرية. فؤاد البهى السيد ( 9V9).علم النفس الإحصائي وغياب العقل البشرى ، القاهرة : دار الفكر العربى. (1) (n)

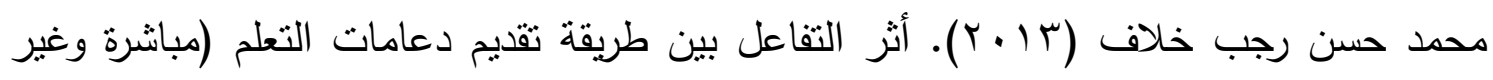
مباشرة) وطريقة تتفيذ مهام الويب (فردية وتعاونية) على التحصيل وتتمية مهارات تطوير موقع تعليمي إلكتروني وجودته لدى طلاب كلية التربية النوعية بجامعة الإسكندرية (رسالة دكتوراه). كلية التربية، جامعة الإسكندرية. محمد عطية خميس (r . . r). منتوجات تكنولوجيا التعليم ، القاهرة :دار الحكمة. محمد عطية خميس (V. . . . الكمبيوتز التعليمي وتكنولوجيا الوسائط المتعددة. القاهرة: دار السحاب.

محمد عطية خميس (9 . . (Y). الدعم الإلكتروني E - Supporting. تكنولوجيا التعليم،9 (Y)؛، $r-1$ محمد عطية خميس(1) (ب).الأصول النظرية والتاريخية لتكنولوجيا التعلم الإككترني، القاهرة، مكتبة دار السحاب للنشر والتوزيع. 
محمـد عيد فارس(1 ( • r) أثز برنامج قائم على الدعامات التعليمية فى تتمية بعض مهارات قراءة الخريطة والدافعية للتعلم لدى تلاميذ المرحلة الابتدائية، المجلة التربوية لجامعة سوهاج ـ العذد

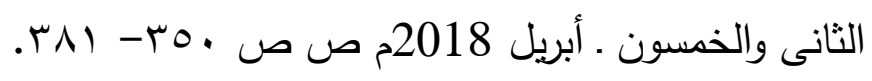

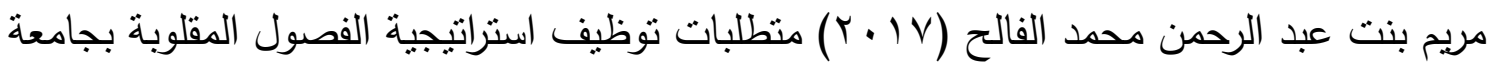
الأميرة نورة بنت عبد الرحمن، مج ا، عه - مجلة العلوم التربوية والنفسية مني حسين احمد حسين (10 • r) فاعلية انماط التعلم المدمج الدوار في تتمية مستوي التقبل التكنولوجي لدي طلاب الدراسات العليا ورضائهم عن استخدامه، رسالة دكتوراه، كلية التربية، جامعة حلوان. مي بنت فهيد بن منديل (10 • ( ). فاعلية استراتيجية الفصول المقلوبة باستخدام الأجهزة المنتقلة في تتمية الاتجاهات نحو البيئة الصفية والتحصيل الدراسي في مقرر قواعد اللغة الإنجليزية لطالبات البرامج التحضيرية بجامعة الإمام محمد بن مسعود الإسلامية، رسالة ماجستير، كلية العلوم الاجتماعية، جامعة الإمام محمد بن سعود الإسلامية. نبيل جاد عزمي (ع ( • ب). بيئات التعلم التفاعلية، القاهرة، دار الفكر العربى. نبيل جاد عزمي، محمد مختار المرادني (· • ( •). أثز التفاعل بين أنماط مختلفة من دعامات التعلم البنائية داخل الكتاب الإلكتروني في التحصيل وكفاءة التعلم لدى طلاب الدراسات العليا

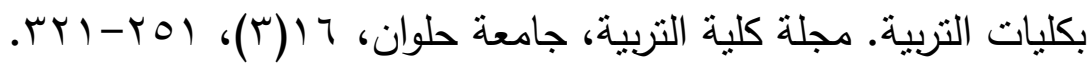
نجلاء يوسف حواس (0 ( ب) فاعلية استخدام استراتيجية الفصل المعكوس في تتمية مهارات التفاعل الصفي لتدربس قواعد اللغة (لطالبات الصف الثاني المتوسط)، دراسات عربية في التربية

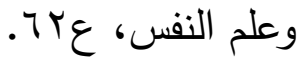
نعيمة محمد فراج رشوان (T (Y). أثز التفاعل بين دعامات التعلم البنائية في برامج الوسائط الفائقة عبر المواقع الإكترونية والأسلوب المعرفي في تتمية بعض الجوانب التعلم لدى طلاب كلية التربية بالعريش. مجلة القراءة والمعرفة، VT I I، 79 - 97. هانى محمد الثيخ (ع ا • ب). أثز التقاعل بين توقيت الدعم التعليمى والاسلوب المعرفى للطلاب فى بيئة التعلم الإككتروني القائمة على الويب r على التحصيل الدراسي وكفاءة التعلم. المؤتمر العلمى الرابع عثر للجميعة المصرية لتكنولوجيا التعليم، المجلد الرابع عثر ، ابريل ؛ ـ ـ . 
وليد يوسف محمد إبراهيم (ع ( r ) ). أثز استخدام دعامات التعلم العامة والموجهة فى بيئة شبكات الويب الاجتماعية التعليمية فى تتمية مهارات التخطيط للبحوث الإجرائية لاى طلاب الدراسات

العليا وتتمية اتجاهاتهم نحو البحث العلمي، دراسات عربية في التربية وعلم النفس ( (ASEP، 53

$$
\begin{aligned}
& 1 \text { () سبتمبر ، } 0 \text { (- . . . . } \\
& \text { ثانيًا المراجع الإنجليزية: }
\end{aligned}
$$

A.Devolder, J.vanBraak \& J.Tondeur (2012). Supporting selfregulated learning in computer-based learning environments: systematic review of effects of scaffolding in the domain of science, education Journal of Computer Assisted Learning, 28 (6), 557-573

Abdellatif Elsafy Elgazzar(2014). Developing E-Learning Environments for Field Practitioners and Developmental Researchers: A Third Revision of an ISD Model to Meet E-Learning and Distance Learning Innovations. Open Journal of Social Sciences, 2014, 2, 29-37 Published Online February 2014 in SciRes. http://www.scirp.org/journal/jss http://dx.doi.org/10.4236/jss.2014.22005

Ahmed BASAL (2015) THE IMPLEMENTATION OF A FLIPPED CLASSROOM IN FOREIGN LANGUAGE TEACHING, Turkish Online Journal of Distance Education-TOJDE October 2015 ISSN 1302-6488 Volume: 16 Number: 4 Article 3.

Azevedo, R. \& Hadwin, A. F. (2005). Scaffolding Self -regulated Learning and metacognition-Implications for the design of Computer based scaffolds. Instructional Science, 33, 367-377.

Bergmann, Jonathan \&Sams, Aaron (2012). "The short history of flipped learning", Flipped Learning network.

Bishop, J. L., \& Verleger, M. A. (2013). The flipped classroom: A survey of the research. In ASEE National Conference Proceedings.Atlanta, GA.

Brame, C., (2013). Flipping the classroom. Vanderbilt University Center for Teaching. [todaysdate] from http://cft.vanderbilt.edu/guides-sub-pages/flipping-the-classroom/.

Buus, L. "Scaffolding Teachers Integrate Social Media Into a ProblemBased Learning Approach?" The Electronic Journal of e-Learning Volume 10 Issue 1 2012, (pp13-22), available online at www.ejel.org . Cagiltay, K.,(2005) . Scaffolding strategies in electronic performance support system : types and challenges. Middle East Technical 
University, Ankara,43,( 1),93-103.

Cara A. Marlowe (2012) . THE EFFECT OF THE FLIPPED CLASSROOM ON STUDENT ACHIEVEMENT AND STRESS, Master of Science, MONTANA STATE UNIVERSITY Bozeman, Montana.

Chong Min Kim, (2011).THE EFFECT OF TEACHERS' SOCIL NETWORKS ON TEACHING PRACTICE AND CLASS COMPOSITION. A Dissertation Submitted in Partial Fulfillment of the Requirements for the degree of Doctor of PHILSOPHY Measurement and Quantitative Methods.

Dabbagh, N., \& Kitsantasm, A. (2005). Using Web-based Pedagogical Tolls as Scaffolds for self-regulated leaning. Instructional Science, 33, 513-540.

Deena S. Disraelly, (2012).Volunteerism through Social Networks for Community-Based Preparedness and Emergency Response. A Dissertation Submitted to the Faculty of the school of Engineering and Applied Science of the George Washington University in Partial Fulfillment of the Requirements for the degree of Doctor of Philosophy. Fulton, K. (2012). Upside down and inside out: Flip your classroom to improve student learning. Learning \& Leading with Technology, 39(8), $12-17$.

Gerald Robert Overmyer(2014) THE FLIPPED CLASSROOM MODEL FOR COLLEGE ALGEBRA: EFFECTS ON STUDENT ACHIEVEMENT, Doctor of Philosophy, Colorado State University. Hannafin, M. (2001). Scaffolding Performance in EPSSS: Bridging Theory and Practice, In C. Montgomerie \& J. Viteli (Eds.), Proceedings of World Conference on Educational Multimedia, Hypermedia and Telecommunications 2001 (pp. 658-663). Chesapeake, VA: AACE.

Harskamp, E. G. (2007). Does the Modality Principle for Multimedia Learning Apply to Science Classrooms?. Learning and Instruction, 17, 465-477.

Heather ,C (2010):Scaffolding, http://www.learnnc.org/lp/pages/5074, Lajoie, S. P. (2005). Extending the Scaffolding Metaphor. Instructional Science, 33, 513-540.

Lange, V. L. (2002). Instructional scaffolding, Retrieved on September 25 ,

2007,fromhttp://condor.admin.ccny.cuny.edu/ group4/Cano/Cano\%20P 
aper.doc.

Learners. Social Media and Language Learning: (R)evolution? Special issue of the Alsic(Apprentissage des Langues et Systèmes d'information et de communication) Journal, 15(1). http://alsic.revues.org/2399

Mary Lane-Kelso, ILT HOD(2015), THE PEDAGOGY OF FLIPPED INSTRUCTION IN OMAN, TOJET: The Turkish Online Journal of Educational Technology - January 2015, volume 14 issue 1.

McNeill, K. L. (2006). Supporting Students' Construction of Scientific Explanations by Fading Scaffolds in Instructional Materials. The Journal of The Learning sciences, 15(2), 153-191.

Mendez, J, A \& Gonzalez, J, G(2010) A reactive blended learning proposal for an introductory control engineering course,Computers \& Education, 54, 856-865.

Molenaar,1 , Carla A. M. van Boxtel, Peter J. C. Sleegers (2011). Metacognitive scaffolding in an innovative learning arrangement, Instructional Science, 39 (6), 785-803

Oliver, R., \& Herrington, J. (2001). Teaching and learning online : a beginner's guide to e-learning and e-teaching in higher education (1st ed.). Australia: Centre for Research in Information Technology and Communications, Edith Crown University.

Park, H.S., \& Kim, Y.H. (2008) • Instructional scaffolding for complex communication tasks: reflecting students needs in design and implementation, AATK Workshop.

Randoll, S., \& Kali, Y. (2004). Design principle for the use of scaffolds. $\quad$ Retrieved from http://kie.berkeley.edu/transitions/scaffold_principles .html Rittle-Johnson, B., \& Koedinger, K. R. (2005). Designing Knowledge Scaffolds to Support Mathematical Problem Solving. Cognition \& Instruction, 23(3), 313-349.

Shapiro, A. M. (2008). Hypermedia Design as Learner Scaffolding. ETR\&D, 56(1), 29-44.

Stewart, T. M. (2007). Enhancing Problem-based Learning Designs with a Single E-Learning Scaffolding Tool: Two Case Studies using Challenge FRAP. Interactive Learning Environments, 15(1), 77-91.

Van Der, R. (2002). Scaffolding as a Teaching Strategy. Adolescent Learning and Development, Section 0500A-fall2002.

Verenikina, I. (2004). From theory to practice: What does the metaphor 
of scaffolding mean to Educators today ?. Outline, Critical Practice Studies, 6(2), Retrieved April 17, 2015, from: http://ojs.statsbiblioteket.dk/index.php/outlines/article/view/2140. Vygotsky, L.S. (1978). Mind and Society: The Development of Higher Mental Processes. Cambridge, MA: Harvard University Press.

Whitehouse, P.W. (2007). Scaffolded Assessment in Virtual Environments: Moo and Moodle, The QSITE State Conference Session Paper, 1-17, Retrieved April 11, 2013, from: http://www.wonko.inf/iwho/scaffolding.htm.

Wikipedia (2015): Instructional Scaffolding: Theory of Scaffolding, Available online at http://en.wikipedia.org/wiki/Instructional_scaffolding 17/4/2015 